\title{
Personalizing Therapy in Advanced Non-Small Cell Lung Cancer
}

\author{
Liza C. Villaruz, MD1, Timothy F. Burns, MD, PHD¹, Vasilis S. Ramfidis, MD ${ }^{1}$, and Mark A. \\ Socinski, MD ${ }^{1}$ \\ ${ }^{1}$ Lung and Thoracic Malignancies Program, University of Pittsburgh Cancer Institute, Pittsburgh, \\ Pennsylvania
}

\begin{abstract}
The recognition that non-small cell lung cancer (NSCLC) is not a single disease entity, but rather a collection of distinct molecularly driven neoplasms, has permanently shifted the therapeutic landscape of NSCLC to a personalized approach. This personalization of NSCLC therapy is typified by the dramatic response rates seen in EGFR mutant NSCLC when treated with targeted tyrosine kinase inhibitor therapy and in $A L K$ translocation-driven NSCLC when treated with ALK inhibitors. Targeted therapeutic approaches in NSCLC necessitate consideration of more invasive biopsy techniques aimed at providing sufficient tissue for both histological determination and molecular profiling in all patients with stage IV disease both at the time of diagnosis and at the time of disease progression. Comprehensive genotyping efforts have identified oncogenic drivers in $62 \%$ lung adenocarcinomas and an increasing proportion of squamous cell carcinomas of the lung. The identification of these oncogenic drivers and the triage of patients to clinical trials evaluating novel targeted therapeutic approaches will increasingly mold a landscape of personalized lung cancer therapy where each genotype has an associated targeted therapy. This review outlines the state of personalized lung cancer therapy as it pertains to individual NSCLC genotypes.
\end{abstract}

\section{Keywords}

non-small cell lung cancer; personalized therapy; oncogenic driver mutations

Lung cancer is the leading cause of cancer mortality in the United States and worldwide. ${ }^{1}$ An estimated 228,190 new cases of lung cancer will be diagnosed in 2013 in the United States alone, and 159,480 lung cancer deaths are estimated to occur. The 5-year survival for all lung cancer patients is a dismal $15 \%$. Historically, non-small cell lung cancer (NSCLC) was treated as a single disease entity, and palliative chemotherapy in the metastatic setting resulted in modest survival prolongation and preservation of quality of life. ${ }^{2-6}$ A series of large randomized controlled phase 3 clinical trials established platinum-based doublets as the standard of care in the treatment of metastatic NSCLC with response rates of 20 to $30 \%$ and a median survival of 8 to 11 months. ${ }^{7-11}$

Address for correspondence Liza C. Villaruz, MD, Division of Hematology/Oncology, University of Pittsburgh Cancer Institute, UPMC Cancer Pavilion, 5150 Centre Avenue, Fifth Floor, Pittsburgh, PA 15232 VillaruzL@ upmc.edu). 
Recent advances in the treatment of metastatic NSCLC have come from recognition that NSCLC is not a single disease entity, but rather a collection of distinct molecularly driven neoplasms. Lynch et al and Paez et al first described a subset of patients with NSCLC harboring activating mutations in the EGFR gene who responded to treatment with EGFR tyrosine kinase inhibitors (TKIs). ${ }^{12,13}$ This discovery permanently shifted the landscape of NSCLC therapy to a personalized approach based on the molecular alterations of a patient's tumor; a paradigm typified not only by targeted therapies in EGFR mutant lung adenocarcinomas but also in $A L K$ translocation driven adenocarcinomas of the lung, and more recently, the therapeutic advances in lung adenocarcinomas harboring ROS1 gene rearrangements and $B R A F$ mutations. ${ }^{14-16}$ This review highlights these and other molecular subsets of NSCLC in which targeted therapies have been shown to be or are potentially more effective than conventional chemotherapy.

\section{Practical Considerations in Molecular Testing}

The historical approach to the diagnosis of lung cancer placed emphasis on noninvasive techniques, often fine needle aspiration (FNA), with the goal of distinguishing histology: small cell lung cancer (SCLC) from NSCLC. Personalized lung cancer therapy has necessitated a shift toward more invasive techniques with an emphasis on core biopsies to ensure adequate tissue to both distinguish histology (not just SCLC from NSCLC, but also nonsquamous from squamous cell carcinoma) and to complete the molecular profiling needed to guide treatment decisions. Protein expression as identified by immunohistochemistry (IHC) is no longer sufficient; patient tumors should undergo molecular testing using direct sequencing techniques and fluorescent in situ hybridization (FISH) for the identification of oncogenic drivers that have or may have important therapeutic implications. Although tumor heterogeneity is an issue, from a pragmatic standpoint, only one site of metastatic disease is typically biopsied; the utility of biopsying multiple sites of metastatic disease is an unresolved question and not routinely done outside of a clinical trial setting. Bone lesions, while often the most accessible site of disease, are no longer acceptable because the decalcification process precludes interrogation of the DNA. The issue of tissue acquisition invariably requires a close collaborative effort between medical oncologists, pulmonologists, thoracic surgeons, and interventional radiologists.

Molecular testing should be performed in all patients with metastatic adenocarcinoma of the lung. Although our knowledge of the oncogenic drivers in squamous cell carcinoma of the lung is increasing, there is limited evidence to guide targeted therapies outside of the clinical trial setting. In the adjuvant setting, there are limited data with regard to the use of targeted agents, and molecular testing is not routinely recommended. The caveat is that, in patients with locally advanced disease with mediastinal lymph node involvement, it is worthwhile at least to consider molecular testing due to a high risk of metastatic disease recurrence. Historically associated with the nonsmoking phenotype, comprehensive profiling of lung adenocarcinomas for EGFR mutations in a North American population reveals a prevalence of $43 \%$ in never-smokers and $11 \%$ in smokers; that is, 1 in 10 smoking patients with lung adenocarcinoma will harbor an EGFR mutation that has important therapeutic implications. ${ }^{17}$ Whereas 85 to $90 \%$ of newly diagnosed lung cancers occur in patients who are smokers, 10 to $15 \%$ of cases occur in never-smokers, making lung cancer in never- 
smokers one of the leading causes of cancer-related mortality. ${ }^{18-20}$ It is therefore important to consider molecular testing for all patients with newly diagnosed metastatic NSCLC of adenocarcinoma histology regardless of smoking history, because of the therapeutic implications of finding an actionable oncogenic driver.

Molecular testing should be performed at the time of diagnosis. A common thread among the oncogenic drivers is the eventual development of resistance to targeted therapies. As such, it is important to consider rebiopsy of patients at the time of progression on a targeted therapy to understand the mechanisms of resistance and possible ways to overcome this resistance. Data from the Lung Cancer Mutation Consortium (LCMC) identified an oncogenic driver in $62 \%$ of lung adenocarcinomas that undergo molecular profiling for 10 of the most common oncogenic drivers and that these oncogenic drivers are $97 \%$ mutually exclusive. ${ }^{21}$ When tissue availability is an issue, it is reasonable to do molecular testing concurrently for the currently actionable genotypes ( $E G F R$ and $A L K$ ), then proceed to more extensive profiling if these initial tests are negative, to triage a patient to a clinical trial for a potentially actionable mutation. ${ }^{21}$ If tissue and resources allow, one can also consider testing more broadly as part of the initial oncogenic screen, and consider utilizing a next-generation sequencing (NGS) platform, which includes both the actionable and the putative oncogenic drivers, as well as genotypic abnormalities for which the functional or therapeutic significance is as yet unknown. Using these techniques, the proportion of actionable oncogenic drivers will only increase over time. Principally, the development of targeted therapeutic approaches in novel molecular subsets of NSCLC is predicated on the adequacy of the biopsy specimen and, of equal importance, the availability and usage of more extensive testing.

\section{Actionable Oncogenic Drivers in NSCLC}

\section{EGFR}

EGFR is a member of the ErbB (or HER) receptor tyrosine kinase family that is a crucial component of the activation of cell signaling pathways, which include the RAS-RAF-MEK pathway and the phosphoinositide 3-kinase (PI3K)-AKT-mammalian target of rapamycin (mTOR) pathway (Fig. 1). ${ }^{22}$ These pathways can in turn be modulated by other receptor tyrosine kinases, such as the insulin-like growth factor-1 receptor (IGF1-R) and mesenchymal epithelial transition factor (MET) and, in concert, effect cell proliferation, local invasion, metastasis, resistance to apoptosis, and angiogenesis. ${ }^{22}$ Sensitizing EGFR mutations most commonly occur as in-frame deletions of exon 19 (45\%) and the $L 858 R$ substitution in exon $21(40-45 \%)$, whereas nucleotide substitutions in exon 18 and in-frame insertions of exon 20 account for another 5\%. ${ }^{23}$ EGFR gene mutations are present in up to $15 \%$ of Caucasians, 30 to $50 \%$ of East Asians, and more than 50\% of Asian never-smokers with adenocarcinoma histology (Fig. 1). ${ }^{21,23}$

The recognition of the central role of targeted therapy in EGFR-mutant lung adenocarcinoma is rooted in the landmark Iressa Pan-Asia Study (IPASS), a randomized phase 3 clinical trial that evaluated the efficacy of gefitinib versus carboplatin/paclitaxel as first-line therapy in patients clinically selected on the basis of adenocarcinoma histology, Asian ethnicity, and never- or light-smoking status. ${ }^{24}$ The IPASS clinical trial illustrates first 
and foremost that targeted therapy with the EGFR TKI gefitinib is superior to conventional chemotherapy in the EGFR mutant population and is associated with a $71.2 \%$ response rate $(\mathrm{RR})$ and a $52 \%$ relative risk reduction for progression-free survival (PFS) compared with chemotherapy ( $p<0.001$; Table 1$)$. The converse is that first-line gefitinib is associated with inferior RRs (1.1\% vs and $23.5 \%$, respectively; Table 1$)$ and worse PFS compared with conventional chemotherapy in the EGFR wild-type population (HR 2.85, $p<0.001$; Table 1). Although targeted therapy is highly effective in the EGFR mutant population, there is potential harm associated with first-line targeted therapy in EGFR wild-type patients; it is therefore insufficient to treat patients with EGFR TKI therapy based on clinical selection criteria alone. It is important whenever possible to test all patients for EGFR activating mutations prior to determining the best first-line therapy. The corollary is that in patients in whom the EGFR mutational status is unable to be determined in a timely manner, as in patients who present in extremis due to large tumor burdens, platinum-based chemotherapy is favored because chemotherapy performs better in EGFR mutant patients compared with EGFR wild-type patients (Table 1).

The benefit of EGFR TKI therapy in the EGFR mutant population has been confirmed in a series of six randomized controlled phase 3 clinical trials evaluating the role of gefitinib, erlotinib, and afatinib in molecularly selected patients with activating EGFR mutations. In this series of trials, EGFR TKIs were consistently associated with RRs of 55 to $86 \%$, doubling the RRs associated with conventional chemotherapy, and were associated with remarkable prolongation in PFS (Table 1). ${ }^{25-30}$ Of note, there was no significant difference in overall survival (OS) in the IPASS clinical trial between gefitinib and chemotherapy in the EGFR mutant population (HR 1.00, $p<0.990$; Table 1); 64.3\% of EGFR mutation positive patients treated with first-line carboplatin/paclitaxel went on to receive second-line EGFR TKI therapy. ${ }^{31}$ Similarly, the phase 3 clinical trials conducted by Rosell et al (EURTAC), Maemondo et al, and Mitsudomi et al (WJTOG 3405) in molecularly selected populations failed to demonstrate a statistically significant OS advantage with targeted therapy. ${ }^{25,27,28}$ These trials had similar rates of crossover from conventional chemotherapy to EGFR TKI therapy at the time of progression: a 76\% crossover rate in Rosell et al, 95\% crossover rate in Maemondo et al, and $91 \%$ crossover rate in Mitsudomi et al. ${ }^{25,27,28}$

The corollary to this is whether the sequencing of EGFR TKI therapy with conventional chemotherapy in patients with EGFR mutant lung adenocarcinoma ultimately impacts patient outcomes. As is illustrated in these clinical trials, it is unlikely that first- versus second-line EGFR TKI therapy significantly impacts OS; however, it is important to note that, although the majority of patients with EGFR mutant lung adenocarcinoma cross over to targeted therapy at the time of disease progression, there remain a small proportion of patients with EGFR mutant lung adenocarcinoma who might experience rapid progression of their disease on first-line conventional chemotherapy and who might miss the opportunity for exposure to second-line EGFR TKI therapy. ${ }^{32}$ First-line EGFR TKI therapy therefore optimizes the chance a patient with an activating EGFR mutation will be exposed to the targeted therapy.

Perhaps the most critical issue in the targeted therapy of EGFR mutant lung adenocarcinoma is the emergence of resistance. Sixty-three to $68 \%$ of patients with acquired resistance to 
EGFR TKIs develop a secondary mutation in exon 20 that results in the T790M substitution altering the affinity of the EGFR adenosine triphosphate (ATP)-(ATPbinding pocket. ${ }^{33,34} \mathrm{In}$ the LUX-Lung 1 clinical trial, the novel irreversible TKI of EGFR and HER2, afatinib, was evaluated in patients who had progression of their disease on erlotinib or gefitinib. ${ }^{35}$ Although this study failed to demonstrate an OS advantage with afatinib compared with best supportive care (HR 1.08, $p=0.74$ ), there was a significant increase in PFS with afatinib (HR 0.38, $p<0.0001$; Table 1). Preclinical mouse models suggest that the combination of afatinib and the monoclonal antibody to EGFR, cetuximab, is highly effective in tumors harboring the $T 790 M$ mutation. ${ }^{36}$ An early-phase clinical trial is currently ongoing to assess the safety and efficacy of this combination in humans (NCT 0109001). Repeat biopsies of patients with EGFR mutant lung adenocarcinomas with acquired resistance to EGFR TKI therapy have also demonstrated amplification of MET in 5 to $20 \%$ of patients, HER 2 amplification in $~ 12 \%$ of patients, $B R A F$ mutations in $1 \%$ of patients, and transformation to small cell lung cancer (SCLC) in 3 to $14 \%$ of patients. ${ }^{33,34,37-41}$ The repeat biopsy at the time of progression is critical to the development of highly effective therapies in patients with acquired resistance to EGFR TKIs.

\section{ALK}

ALK is a receptor tyrosine kinase that is believed to play a role in the development of the brain and exerts its effects on specific neurons in the nervous system. ${ }^{42}$ It modulates several signaling pathways such as the PI3K-AKT, MAPK, and JAK-STAT pathways in synergy with other receptor tyrosine kinases (Fig. 1). The interest in $A L K$ soared in 2007 when the fusion of $A L K$ with the $E M L 4$ gene was identified in a group of NSCLC patients. ${ }^{43}$ Multiple $E M L 4-A L K$ variants, the predominant $A L K$ fusion in NSCLC, have been identified, as well as other fusion products, including $K I F 5 B-A L K, T F G-A L K$, and $K L C 1$ $A L K^{44}$ The fusion of $E M L 4-A L K$ results from a small inversion within chromosome $2 \mathrm{p}$ leading to the fusion of $E M L 4$ to the intracellular kinase domain of $A L K$. Several studies have revealed the transforming and oncogenic activity of EML4-ALK in vivo and in vitro. ${ }^{45-47}$ In unselected NSCLC patients, the frequency of $A L K$ rearrangements is 5\%, but clinicopathological features demonstrate that patients with adenocarcinoma histology, males, with a light- or never-smoking history and no other oncogenic drivers are more likely to harbor $A L K$ rearrangements. ${ }^{48,49}$ Data from the LCMC indicate a frequency of $8 \%$ in lung adenocarcinomas (Fig. 1). ${ }^{21}$

Crizotinib, a multitargeted small molecule TKI that inhibits not only ALK but MET and ROS 1 as well, was approved by the U.S. Food and Drug Administration (FDA) in 2011 based on phase 1 and 2 clinical trial data. The first results of the phase 1 trial were presented by Kwak et al, in which $82 A L K$ positive NSCLC patients received crizotinib with an RR of $57 \% .{ }^{14}$ The updated analysis of this trial presented results on $149 A L K$-positive NSCLC patients in whom crizotinib was associated with an RR of $60.8 \%$, including three patients with complete responses, and a PFS of 9.7 months (Table 1). ${ }^{50}$ A single-arm phase 2 clinical trial evaluating the efficacy of crizotinib in previously treated $A L K$-positive patients (PROFILE 1005) echoed these results; in 255 patients evaluable for response, crizotinib was associated with an RR of 53\% and a PFS of 8.5 months (Table 1). ${ }^{51}$ Furthermore, $A L K$ positive patients who receive crizotinib have improved survival compared with $A L K$ - 
positive patients who are crizotinib-naive as demonstrated in a retrospective analysis by Shaw et al. ${ }^{52}$ More specifically, patients who received crizotinib compared with those who did not had a 1 -year OS of $70 \%$ versus $44 \%$ and a 2 -year OS of $55 \%$ versus $12 \%$, respectively.

In the first-line setting, the ongoing PROFILE 1014 phase 3 randomized clinical trial is evaluating the efficacy of crizotinib versus platinum/pemetrexed in $A L K$-positive NSCLC patients with the primary end point of PFS (NCT01154140). In the second-line setting, the phase 3 randomized clinical trial, PROFILE 1007, compared crizotinib with standard chemotherapy (pemetrexed or docetaxel) in $A L K$-rearranged NSCLC. ${ }^{53}$ This study accrued a total of 347 patients and demonstrated a PFS of 7.7 months with crizotinib versus 3 months for chemotherapy (HR $0.49, p<0.001$; Table 1 ) and an RR of $65 \%$ with crizotinib versus $20 \%$ with chemotherapy ( $p<0.001$; Table 1$)$. The immature OS results showed no difference between the two arms of the trial, but crossover among patients in the chemotherapy group should be taken into account in evaluating the final survival analysis.

Despite the impressive response rates of crizotinib in $A L K$-positive NSCLC patients, the time-limited efficacy of the drug reveals the need of exploring the mechanisms of resistance and developing second-generation ALK inhibitors. Several mechanisms of resistance have been described, the most common of which is a secondary resistance mutation located in the ALK tyrosine kinase domain, the L1196M mutation, which acts as a gatekeeper mutation analogous to the T790M mutation in EGFR mutant NSCLC. ${ }^{54-56}$ Additional resistance mutations that have been described are the $61269 A$ substitution in the ATP binding pocket and the $G 1202 R$ and $G 1206 Y$ mutations in the solvent-exposed region of the kinase domain. ${ }^{57,58}$ In a series of $11 A L K$-positive patients with acquired resistance to crizotinib, 2 patients, one with a resistance mutation, exhibited amplification of $A L K .{ }^{57}$ Indeed, EML4$A L K$ gene amplification was associated with the emergence of resistance in EML4-ALK NSCLC cell lines treated with increasing doses of crizotinib. ${ }^{55}$ In addition to secondary $A L K$ mutations and $A L K$ gene amplification, activation of other kinases, including increased autophosphorylation of EGFR and amplification of KIT, could contribute to maintenance of downstream signaling and diminish the efficacy of crizotinib. ${ }^{58,59}$ Finally, $K R A S$ mutations were identified in 2 out of 14 patients with acquired resistance to crizotinib in a study by Doebele et al, implicating KRAS mutations as a possible resistance mechanism. ${ }^{57}$

LDK378 is a potent and selective second-generation ALK inhibitor, which was evaluated in a phase 1 clinical trial of 88 evaluable patients with $A L K$-positive NSCLC and was associated with an RR of $70 \% .{ }^{60}$ In the subset of 64 patients with crizotinib-resistant disease, LDK378 was associated with a remarkable RR of $73 \%$ (Table 1). CH5424802 is another second-generation ALK inhibitor, which was evaluated in a phase $1 / 2$ clinical trial in crizotinib-naive $A L K$-positive NSCLC patients and was associated with an impressive $93.5 \%$ RR in 46 evaluable patients. ${ }^{61}$ Ganetespib, a potent inhibitor of heat shock protein 90 (HSP 90), was evaluated as monotherapy in a phase 2 clinical trial of genotypically defined NSCLC patients, in which four patients experienced partial responses, all of whom harbored an ALK gene rearrangement retrospectively detected by FISH. ${ }^{62}$ This appears to be an HSP 90-dependent effect because other HSP 90 inhibitors, AUY922 and IPI-504, have also been 
associated with responses in $A L K$-positive NSCLC patients. ${ }^{63,64}$ Ganetespib induces the degradation of the EML4-ALK protein by targeting the chaperone dependency of ALK, rather than the kinase directly. The known and unknown mechanisms of resistance remain to be further elucidated to develop more effective therapeutic strategies.

\section{ROS1}

ROS1 is a receptor tyrosine kinase of the insulin receptor family with $49 \%$ homology with ALK within the tyrosine kinase domain and 77\% identity with ALK in the ATP-binding site. ${ }^{65,66}$ ROS1 gene rearrangements were originally described in glioblastoma multiforme, resulting from fusion with the $F I G$ gene, and have been shown to be transforming in transgenic mice.$^{67-70}$ To date, seven distinct ROS1 gene fusions have been described in solid tumors leading to aberrant kinase activity and activation of the PI3K-AKT-mTOR pathway, the RAS-RAF-MEK pathway, in addition to the Src-homology 2 domain-containing phosphatase (SHP)-1 and -2 pathways and the vav 3 guanine nucletotide exchange factor 1 (VAV3) pathway, with subsequent aberrant cell proliferation, survival, metastases, and migration (Fig. 1). ${ }^{71}$ Using FISH, this oncogenic driver was identified in $1.7 \%(18 / 1,073)$ patients with NSCLC; it occurred in a mutually exclusive fashion with $A L K$ translocations and was more likely to be present in patients who were younger, never-smokers with adenocarcinoma histology, with a predilection for Asian ethnicity. ${ }^{15}$ A Japanese series identified ROS1 fusions in $0.9 \%$ NSCLC patients $(13 / 1,476)$ and $1.2 \%$ patients with adenocarcinoma histology $(13 / 1,116) .{ }^{72}$ Using IHC and confirming with FISH or reverse transcriptase polymerase chain reaction, Rimkunas et al reported ROS1 rearrangements in $1.6 \%$ NSCLC (9/556) and 3.3\% (8/246) lung adenocarcinomas from Chinese patients. ${ }^{73}$ Taken together, ROS1 gene rearrangements occur at a frequency of $\sim 1$ to $3 \%$ (Fig. 1). Crizotinib has been shown to inhibit ROS1 phosphorylation in the ROS1-rearranged NSCLC cell line HCC78 and in HEK 293 cells transfected with a CD74-ROS1 fusion gene expression construct. ${ }^{15}$ To test if crizotinib has activity in ROS1-rearranged NSCLC, a 31year-old never-smoking patient with ROS1 -positive bronchoalveolar carcinoma was enrolled on the expansion cohort of the original phase 1 clinical trial of crizotinib. Having presented with hypoxia, this patient had complete resolution of his respiratory insufficiency after 2 weeks of therapy, with near complete response in his multifocal tumor on restaging scans at 8 weeks, suggesting exquisite sensitivity of ROS1-positive NSCLC to inhibition with crizotinib. ${ }^{15}$ In a subsequent series of 25 patients with ROS1 -positive NSCLC, crizotinib was associated with a $56 \%$ response rate. ${ }^{16}$ The ROS1-rearranged NSCLC expansion cohort of the original crizotinib phase 1 clinical trial is currently accruing to further assess the efficacy of this targeted therapy (NCT 00585195).

\section{BRAF}

BRAF is a member of the RAF kinase family of serine/threonine protein kinases, which have diverse roles in mediating proliferation and survival. Upon activation by RAS, BRAF phosphorylates MEK leading to activation of ERK and the ERK signaling pathway (Fig. 1). Several $B R A F$ mutations have been described in cancers, most prominently in melanoma (60\%), colorectal (8-15\%), and lung (2\%) cancers (Fig. 1). ${ }^{74-77}$ The most commonly observed mutation in $B R A F$ is a valine (V) to glutamic acid (E) substitution at residue 600 (BRAF V600E). This substitution results in mutant BRAF protein, which no longer requires 
dimerization for its activity. Therefore the BRAF V600E protein is constitutively active and is transforming in vitro. ${ }^{78}$ Although the $B R A F^{V 600 E}$ mutation accounts for almost 80 to $90 \%$ of all $B R A F$ mutations in metastatic melanoma, only $50 \%$ of $B R A F$ mutations are $B R A F^{V O O O E}$ in metastatic NSCLC, and additional mutations, which have transforming ability in vitro, have been identified including $B R A F^{G 469 A}(39 \%)$ and $B R A F^{D 593 G}(11 \%) .{ }^{77}$ Lung cancer patients with $B R A F$ mutations are more likely to be Caucasian and current or former smokers.

Two selective BRAF inhibitors, vemurafenib and dabrafenib, have shown significant clinical activity in $B R A F^{V 600 E}$ mutant NSCLC in the metastatic setting. ${ }^{79-81}$ Recently, interim results of a phase 2 study with the BRAF-specific inhibitor dabrafenib in $B R A F$ V600E mutation-positive NSCLC patients was presented at the 2013 American Society of Clinical Oncology Annual Meeting. ${ }^{81}$ This trial enrolled patients with stage IV $B R A F^{V 600 E}$ mutant disease who had progressed after at least one line of prior chemotherapy. At the time of analysis, efficacy data were available on the first 20 patients and safety data on the first 25 patients. Remarkably, the study was positive for its primary end point of investigatorassessed overall RR. The investigators observed a 54\% overall RR with durable responses as long as 49 weeks. The overall disease control rate was $60 \%$, including a partial responses rate of $40 \%$ and stable disease rate of $20 \%$. PFS and OS data were not mature enough at the time of presentation. ${ }^{81}$ Regardless, the observed ORR and overall disease control rates compare favorably with what has previously been seen in metastatic melanoma where the BRAF inhibitor, vemurafenib, is FDA approved in the first-line setting. ${ }^{78}$ Currently, there is tremendous enthusiasm that dabrafenib may be effective therapy for $B R A F^{V 600 E}$ mutant NSCLC. Unfortunately, similar to melanoma, acquired resistance to BRAF inhibitors in NSCLC has already been observed. ${ }^{82} \mathrm{~A}$ study is already under way examining the use of MEK inhibitors in $B R A F^{V 600 E}$ mutant NSCLC, and this may be one strategy for overcoming acquired resistance (NCT00888134). Finally, although 50\% of $B R A F$ mutations in lung cancer are non- V600E mutations, little is known about the potential response to either BRAF-specific inhibitors or downstream inhibition through MEK1 inhibitors.

\section{Putative Oncogenic Drivers}

In addition to the oncogene drivers already discussed and the mutant $K R A S$ yet to be discussed, there are a series of putative oncogene drivers (MET, KIF5B-RET, HER2, $P I K 3 C A, A K T 1, M A P K 2 K 1)^{83}$ for which mutational testing is being performed at many institutions or through the LCMC. In addition, we are continuing to find new translocations that may be targetable (NTRK1 gene fusions). For many of these targets, the therapeutic significance of these alterations has not been determined, but inhibitors of these pathways may have a role in a small subset of patients.

\section{MET}

The MET protein is a receptor tyrosine kinase, which, upon binding its only known physiological ligand, hepatocyte growth factor/scatter factor (HGF/SF) activates a series of downstream processes that are critical for oncogenesis, including cell proliferation, survival, invasion/migration, and metastasis. ${ }^{84}$ Upon binding of HGF to the Sema domain of MET, 
dimerization and subsequent autophosphorylation occur, leading to the activation of the MET receptor and downstream signaling through the RAS-ERK, PI3K-AKT-mTOR, and STAT pathways (Fig. 1). ${ }^{84} \mathrm{In}$ addition, activated MET has been demonstrated to have significant crosstalk with the EGFR pathway. ${ }^{84}$ Aberrant signaling through the MET pathway has been observed in several tumor types and can occur through mutation, amplification or overexpression of the $M E T$, or overexpression of $H G F^{85}$ Although mutations in the $M E T$ gene are rare in NSCLC, ${ }^{86}$ the $M E T$ gene is amplified in adenocarcinoma of the lung in 2 to $20 \%$ of cases examined. ${ }^{87-89}$ Recently, a large study by the LCMC suggested the MET gene is only amplified in 1\% of adenocarcinomas of the lung (Fig. 1). ${ }^{21}$ Interestingly, MET amplification is a common mechanism of acquired resistance to EGFR TKIs and is found in up to $20 \%$ of patients who have acquired resistance to EGFR TKIs. ${ }^{40,41}$ In addition to mutations or amplification of MET, the MET protein is overexpressed in a significant number of cases of advanced NSCLC. In fact, a recent phase 2 study (yet to be discussed) has suggested that MET may be overexpressed in 54\% of advanced NSCLC. ${ }^{90}$

Given the critical role of the MET pathway in tumorigenesis, metastasis, and acquired resistance to targeted therapy, there are more than a dozen MET-targeted therapies in clinical trials that target its ligand HGF (rilotumumab, ficlatuzumab), the extracellular portion of the MET receptor (onartuzumab-METMab), or the intracellular kinase activity of the MET receptor (tivantinib, crizotinib, cabozantinib) ${ }^{85}$ Although anti-MET therapy as monotherapy or in combination in unselected patient populations has been disappointing to date, a recent phase 2 trial comparing onartuzumab (MetMAb) and erlotinib versus erlotinib alone in the second-and third-line setting for metastatic NSCLC found a significant advantage in PFS and OS for the combination in the "MET high" population. ${ }^{90}$ Furthermore, $54 \%$ of patient samples were defined as MET high (50\% or greater cells on the diagnostic slide with a staining intensity of 2 or 3), which suggests that a significant fraction of patients with metastatic lung cancer may be at least partially MET dependent. This concept is now being tested in global phase 3 randomized, multicenter, double-blind, placebo-controlled study testing this combination versus erlotinib only in the MET high population (NCT01456325). In addition to monoclonal antibodies targeting MET, there are several MET tyrosine kinase inhibitors in development and/or FDA-approved agents (crizotinib), and these agents are being used to target the MET pathway in mutationally defined subsets such as $K R A S$ mutant NSCLC (discussed in the KRAS section) and in the acquired resistance to EGFR TKI therapy setting. ${ }^{91}$ Interestingly, several case reports have suggested that patient tumors with MET amplification may be MET "addicted," and dramatic responses have been seen with MET TKI monotherapy. ${ }^{92,93}$ These observations have led to the development of a METamplified-only cohort on a current phase 1 study looking at crizotinib in advanced NSCLC as well as other solid tumor types (NCT00585195).

\section{KIF5B-RET}

The KIF5B-RET fusion oncogene involves the RET receptor tyrosine kinase, which is involved in cell proliferation, neuronal navigation, cell migration, and differentiation. ${ }^{94}$ Although germline and somatic mutations in RET cause the multiple endocrine neoplasia type 2 syndrome and medullary thyroid carcinoma, somatic $R E T$ fusion products, such as 
CCDC6-RET and NCOA4-RET are associated with the sporadic and radiation-induced forms of papillary thyroid carcinoma. ${ }^{95-99}$ The KIF5B-RET fusion protein retains the full RET kinase domain and the KIF5B coiled-coil domain, which likely participates in homodimerization leading to aberrant activation of the kinase function of RET. ${ }^{100-102}$ Indeed, KIF5B-RET expression in H1299 human lung cancer cells leads to phosphorylation of the activation loop of the RET kinase site in the absence of serum activation, indicative of aberrant RET kinase activity. ${ }^{103}$ Expression of exogenous KIF5B-RET results in morphological transformation and anchorage-independent growth of NIH3T3 fibroblasts, which is suppressed by treatment with the multi-tyrosine kinase inhibitor, vandetanib. ${ }^{103}$

The KIF5B-RET fusion transcript has been demonstrated in 1.9\% (6/319) of Japanese lung adenocarcinomas, $1.3 \%(1 / 80)$ of U.S. lung adenocarcinomas, and $0 \%(0 / 34)$ of Norwegian lung adenocarcinomas. ${ }^{103}$ In another Japanese series, RET fusions were demonstrated in $0.9 \%(13 / 1,482)$ of NSCLC patients and $1.2 \%(13 / 1,119)$ of lung adenocarcinoma patients. ${ }^{72}$ A surgical series concurred; RET fusions occurred in 1.4\% (13/936) of NSCLCs and $1.7 \%(11 / 633)$ of lung adenocarcinomas and were more likely associated with a poorly differentiated histology, a never-smoking status, and a younger age. ${ }^{104} \mathrm{In}$ a former light smoker with lung adenocarcinoma, a KIF5B-RET translocation was demonstrated after molecular profiling was unrevealing for other oncogenic drivers (mutations in $E G F R$, KRAS, BRAF, HER2, MET amplification and rearrangements of ROS1 and ALK). ${ }^{105}$ The patient, who was refractory to first-line platinum-based chemotherapy, was treated with vandetanib with a complete response after 4 weeks of treatment. Vandetanib (NCT 01823068) and the other RET tyrosine kinase inhibitors, cabozantinib (NCT 01639508) and ponatinib (NCT 01813734), are the subjects of ongoing phase 2 clinical trials assessing their efficacy in patients with RET-driven NSCLC.

\section{HER2}

The human epidermal growth factor 2 (HER2, Neu, ErbB-2) protein, which is encoded by the $E R B B 2$ gene, is a member of the erbB1 family of receptor tyrosine kinases, which include EGFR (HER1), HER3, and HER4. There are no known ligands for HER2, rather HER2 is activated by homo- or heterodimizeration with other HER family members. ${ }^{106}$ Activation drives proliferation and survival through its downstream PI3K-AKT and MEKERK pathways (Fig. 1). HER2 when overexpressed or amplified is an oncogenic driver in metastatic breast cancer; however, the role of the HER2 pathway in lung cancer is less well characterized. Previous studies have demonstrated that the ERBB2 gene is amplified in 10 to $20 \%$ of lung cancer tumors, ${ }^{107}$ and the HER 2 protein is overexpressed in $~ 20 \%$ of NSCLC; however, this does not appear to predict response to HER2-targeted therapy. ${ }^{108}$ HER2 mutations are seen in $\sim 2$ to $4 \%$ of NSCLC and are more common in females, nonsmokers, and adenocarcinoma histologies (Fig. 1). ${ }^{109-12}$ Furthermore, these mutations appear to be mutually exclusive with other known driver mutations (EGRF, ALK, KRAS).${ }^{12} \mathrm{~A}$ recent retrospective analysis identified $H E R 2$ mutations in $65(1.7 \%)$ out of 3,800 patients tested and analyzed the outcome of the 22 HER 2 mutant patients that received HER2-directed therapy (trastuzumab, afatinib). Remarkably, an overall response rate and disease control rate of 50\% and $82 \%$, respectively, were observed, suggesting that HER2-directed therapy may be beneficial in HER2 mutant NSCLC. ${ }^{112}$ There are several studies that are now testing 
this prospectively with HER-targeted TKIs (NCT01827267) or trastuzumab (NCT00004883 and NCT00758134).

\section{Other Putative Targets}

Alterations in the majority of receptor tyrosine kinases described earlier and KRAS lead to activation of the PI3K-AKT and MAPK pathways (Fig. 1). There has thus been a great interest in targeting these pathways in adenocarcinoma of the lung. PI3K is a member of the lipid kinase family and plays an important role in cell growth proliferation and survival.

Mutations in the PI3K family of lipid kinases are found in the catalytic subunit of PI3K, in the p110a, which is encoded by the PIK3CA gene. Mutations are found in $~ 1 \%$ of adenocarcinomas and do not appear to be mutually exclusive with other known oncogene drivers ( $E G F R, K R A S, A L K$; Fig. 1 ). ${ }^{21,113}$ In adenocarcinoma of the lung in possible contrast to squamous cell carcinoma of the lung, it is not clear whether PIK3CA mutations represent a true driver oncogene, and single-agent activity has been disappointing to date. ${ }^{14,115}$ Signaling through the PI3K pathway leads to activation of the AKT1/protein kinase B, which is a Ser-Thr kinase that phosphorylates several downstream substrates, leading to diverse effects on cellular metabolism, survival, and proliferation (Fig. 1). Mutations in the AKT1 gene have been observed in 1\% of NSCLC and appear to be limited to squamous cell carcinoma of the lung (Fig. 1). ${ }^{21,116,117}$ The AKT1 inhibitor MK2206 is currently being tested as a single agent and in combination with other pathways inhibitors or cytotoxic agents, and efficacy results are still pending (NCT00848718 and NCT01294306). ${ }^{118}$

Mitogen-activated protein kinase 1 (MAPKK1) or MEK1 is a Ser-Thr kinase that activates MAPK (ERK1), leading to cellular proliferation (Fig. 1). MAPKK1 is a direct downstream target of BRAF, and mutations have been found in 1\% of NSCLC (Fig. 1). ${ }^{119}$ Although these mutations are mutually exclusive of EGFR, KRAS, HER2, and BRAF mutations, it is not known whether this represents a true driver oncogene. Several MEK1 inhibitors are currently being tested in selected (KRAS mutant) ${ }^{120-122}$ and unselected populations (NCT01809210) and appear to show activity in combination with chemotherapy, at least in the $K R A S$ mutant cohort (yet to be described).

In addition to the pathways already described, novel potential driver oncogenes are still being identified in meta-static adenocarcinoma of the lung. Recently, two novel NRTK1 gene fusions (MPRIP-NTRK1 and CD74-NTRK100) were identified that result in a constitutively active TrkA kinase and ability to transform cells in vitro. Interestingly, several panTrk inhibitors as well as crizotinib have activity against these translocations in vitro. ${ }^{123}$ Because NRTK1 alterations may be present in as many as 3\% of pan negative (EGFR, $K R A S, A L K, R O S 1$ wild-type) patients, NRTK1 fusions may be a promising target in a small subset of patients. Interestingly, a recent report has described that the commonly observed translocation in acute lymphoblastic leukemia, $E 2 A-P B X 1$, is also present in $12.5 \%$ of NSCLC cases, although it does not appear to be mutually exclusive with other known driver mutations. ${ }^{124}$ Interestingly, leukemias expressing this translocation appear to be sensitive to dasatinib ${ }^{125}$ and as such, E2A-PBX1 translocations may represent a novel therapeutic target for lung cancer. 


\section{Unmet Needs}

\section{KRAS}

The KRAS protein or $\mathrm{V}-\mathrm{K}_{\mathrm{i}}$-ras2 Kirsten rat sarcoma viral oncogene homologue is a member of the RAS family of guanosine triphosphatases. When bound to guanosine-5'-triphosphate and recruited to the plasma membrane, KRAS is activated and signals through multiple growth regulatory cascades including the RAF/MEK/ERK, PI3K/AKT/mTOR and RAL pathways (Fig. 1). KRAS activity is normally tightly regulated by a series of GTPaseactivating proteins (GAPs) and guanine-nucleotide exchange factors (GEFs) as well as upstream activation and recruitment to the plasma membrane. In a variety of solid tumors, $K R A S$ is mutated at codon position 12,13 , or 61 , leading to a loss of intrinsic GTPase activity, and conversely becomes constitutively active, leading to cellular transformation. ${ }^{126}$ The first mutations in the $K R A S$ oncogene in NSCLC were discovered almost 3 decades $\mathrm{ago}^{127,128}$; however, there are no current therapies targeting this critical oncogene. ${ }^{129}$ KRAS is mutated in one third of all malignancies and $\sim 25 \%$ of all NSCLC (Fig. 1 ). ${ }^{21,129}$ As such, mutant $K R A S$ is the most frequently observed driver mutation in metastatic adenocarcinoma of the lung. Furthermore, NSCLC patients with a KRAS mutation have an increased risk of recurrence in early-stage disease and have a worse prognosis with metastatic disease. ${ }^{129,130}$ Although KRAS mutations are found in both never-smokers and smokers, never-smokers are more likely to have transition mutations versus transversion mutations compared with current or former smokers. ${ }^{131}$ In an analysis of the KRAS amino acid substitutions in NSCLC patients treated on the Biomarker-integrated Approach of Targeted Therapy for Lung Cancer Elimination (BATTLE) trial, the presence of GLY $\rightarrow$ YS or GLY $\rightarrow$ VAL substitutions was associated with worse outcomes. ${ }^{132}$ Although other studies were not suggestive of prognostic differences in the spectrum of $K R A S$ amino acid substitutions, one series has suggested a worse prognosis with $K R A S$ codon 13 mutations versus codon 12 mutations. ${ }^{133,134}$

Given its importance in NSCLC, multiple strategies have been proposed to target the KRAS pathway, including direct inhibition of the KRAS protein, use of antisense strategies, inhibition of its localization to the plasma membrane, and inhibition of its downstream effectors. To date none of these strategies have been successful. ${ }^{126}$ However, several novel therapeutics are currently in early-phase clinical trials for mutant $K R A S$ and have demonstrated some promise. A recent phase 2 double-blind, randomized study of the MEK1/MEK2 inhibitor selumetinib plus docetaxel versus docetaxel plus placebo as secondline treatment for advanced $K R A S$ mutant NSCLC demonstrated efficacy. Median PFS was 5.3 months in the selumetinib group and 2.1 months in the placebo group (HR 0.58; $p$ $=0.014)$. Remarkably $16(37 \%)$ patients in the selumetinib group versus zero patients in the placebo group had an objective response $(p<0.0001)$. Although the primary end point of OS was not met, there was a strong trend toward an improvement in median OS: 9.4 months in the selumetinib group compared with 5.2 months in the placebo group (HR $0.80 ; p=21$ ). Unfortunately, this combination was accompanied by significant neutropenia, and further investigation of this combination in KRAS mutant NSCLC will be dependent on the development of revised dosing schedules of the combination. ${ }^{135}$ However, a second MEK1/ MEK2 inhibitor in combination with docetaxel in a phase $1 / 1 \mathrm{~b}$ trial in second-line treatment 
for advanced KRAS mutant NSCLC has demonstrated efficacy and appears to have an improved side-effect profile. ${ }^{121}$

In addition to inhibiting MEK1 in KRAS mutant NSCLC, there has been an effort to inhibit parallel pathways (EGFR and MET) in $K R A S$ mutant NSCLC. A recent phase 2 trial examined the combination of a putative MET inhibitor (ARQ-197/tivantinib) and the EGFR inhibitor (erlotinib) versus erlotinib alone in second-line treatment of NSCLC. ${ }^{136}$ Although the study did not meet its prespecified primary end point (PFS), a preplanned exploratory survival analysis revealed a trend toward benefit in nonsquamous and $E G F R$ wild-type populations. Remarkably, in the $16 K R A S$ mutant patients in the study, a significant benefit in PFS was seen (HR 0.18; $p<0.01$; interaction $p=0.006$ ) and a trend for OS (HR $0.43 ; p$ $=0.17)$. These findings led to an LCMC phase 2 trial of the combination of tivantinib and erlotinib versus standard chemotherapy in the second-line treatment for advanced $K R A S$ NSCLC (NCT01395758). This trial is currently nearing its accrual, and we are awaiting the results of this study.

In addition to these current efforts, the role of HSP 90 inhibitors such as ganetespib and IPI-504 are being tested based on interesting preclinical efficacy in KRAS mutant cell lines and mouse models. ${ }^{137,138}$ Interestingly, early-phase trials with ganetespib either as monotherapy ${ }^{62}$ or in combination with chemotherapy ${ }^{139}$ or other targeted therapies have suggested that KRAS mutant tumors may benefit from HSP 90 inhibitor therapy. This hypothesis is currently being tested in several ongoing clinical trials with ganetespib (Galaxy 2 trial) ${ }^{140}$ and other HSP 90 inhibitors such as IPI-504 (NCT01348126, NCT01798485, NCT01427946). Finally, inhibition of the mTOR pathway may benefit patients with $K R A S$ mutant NSCLC. A recent study examined the activity of the mTOR inhibitor ridaforolimus in KRAS mutant advanced NSCLC in the second- and third-line setting. ${ }^{141}$ This phase 2 study used a randomized discontinuation design and found that patients with stable disease at 8 weeks who were randomized to continue therapy had a significantly improved PFS; 4 months versus 2 months for the placebo. In addition, there was a trend toward improved median OS from randomization (18 months vs 5 months, HR 0.46, $p=0.09$ ). Because the response rate (partial responses: $1 / 79$ patients) was extremely low with ridaforolimus it is likely that future studies with mTOR inhibition will require the mTOR inhibitor to be combined with a second agent.

\section{NSCLC of Squamous Cell Histology}

An issue of critical importance is the elucidation and development of targeted therapeutic approaches in the second most common type of lung cancer, squamous cell carcinoma (SQCC) of the lung. Although EGFR and KRAS mutations occur quite commonly in adenocarcinoma of the lung, they are rarely associated with SQCC; indeed, in a series of 95 SQCC, verified by IHC as $\mathrm{p} 63$ positive and TTF-1 negative, there were no EGFR or KRAS mutations identified. ${ }^{142}$ While initial genotyping identified 16 EGFR/KRAS mutant "SQCCs," detailed morphological and IHC reevaluation led to the reclassification of these tumors as either adenosquamous carcinoma or poorly differentiated adenocarcinoma with squamoid morphology, suggesting that the occurrence of these oncogenic drivers in SQCC are a consequence of incomplete sampling or morphological overlap. ${ }^{142}$ 
Comprehensive genotyping of SQCC was performed as part of The Cancer Genome Atlas (TCGA) project with the goal of identifying potential opportunities for therapy. The most significantly mutated genes were TP53 (81\% SQCC samples), MLL2 (20\%), PIK3CA (16\%), and $C D K N 2 A(15 \%)$. Occurring less frequently were mutations in KEAP1, NFE2L2, $P T E N, H L A-A, N O T C H 1$, and RB1. ${ }^{143}$ Mutation and copy number alterations of NFE2L2 and KEAP1 and/or deletions of CUL3 (genes involved in the oxidative stress response) were present in $34 \%$ of cases.

Overexpression/amplification of SOX2 and TP53, loss-of-function mutations in NOTCH1 and NOTCH2 and ASCL4, and focal deletions in FOXP1 (all genes with known roles in squamous cell differentiation) were found in $44 \%$ of samples. ${ }^{143}$ Only one sample harbored a $K R A S$ codon 61 mutation, and although no EGFR exon 19 deletion or $L 858 R$ substitutions were identified, EGFR amplifications were demonstrated in 7\% cases and two EGFR L861Q substitutions were identified (a sensitizing mutation to erlotinib and gefitinib). ${ }^{143}$ Ninety-six percent of SQCCs harbored one or more mutations in tyrosine kinases, serine/threonine kinases, PI3K catalytic and regulatory subunits, nuclear hormone receptors, G-proteincoupled-receptors, proteases, and tyrosine phosphatases; 50 to $77 \%$ of the mutations were predicted to have medium or high functional effects, suggesting the presence of new potential therapeutic targets. ${ }^{143}$

Fibroblast growth factor receptor 1 (FGFR1) is a receptor tyrosine kinase that regulates cell proliferation by the MAPK and PI3K pathways. In an analysis of 155 SQCCs using a single nucleotide polymorphism array, frequent and focal amplification was identified on $8 \mathrm{p} 12$, which includes FGFR 1. ${ }^{144}$ This region was amplified at high amplitude (four or more copies) in $9.7 \%$ (15/155) cases, 11 of whom were smokers and none were never-smokers, and no FGFR1 amplification was identified in a cohort of lung adenocarcinoma patients. ${ }^{144}$ Patients with SQCC and very high FGFR 1 amplification (copy number $>9$ by FISH) had a nonsignificant trend toward inferior survival compared with patients without FGFR1 amplification. ${ }^{144}$ The prevalence was verified in independent cohorts of SCQQ patients in whom FGFR1 amplification was identified in $21 \%$ of patients (12/57) and 22\% (34/153) of patients; in the latter series, 27 were current smokers and none were never-smokers. ${ }^{145}$ Treatment with the non-isoform-specific FGFR inhibitor PD173074 induces apoptosis in FGFR 1 -amplified cells and tumor shrinkage in mice engrafted with FGFR 1-amplified cells. ${ }^{144}$ The dual FGFR/vascular endothelial growth factor receptor (VEGFR) inhibitor brivanib (BMS-582664) was evaluated in a randomized discontinuation study of unselected patients with advanced solid tumors and was associated with no responses ${ }^{146}$; there are, however, ongoing phase 2 clinical trials evaluating novel FGFR inhibitors in the targeted FGFR1 amplified SQCC population (NCT 01861197; NCT 01795768).

DDR2 is a receptor tyrosine kinase that binds collagen as its endogenous ligand and promotes cell migration, proliferation, and survival. Sequencing of $D D R 2$ in a series of 290 primary SQCCs demonstrated a frequency of 3.2\% (9/277) and identified mutations both in the kinase domain and in other regions of the protein sequence; no copy number alterations were identified. ${ }^{147}$ Of the limited clinical information available in this case series, there was no association between $D D R 2$ mutations and age, sex, or smoking history. ${ }^{147}$ The tyrosine kinase inhibitor, dasatinib, was found to inhibit growth in SQCC cell lines harboring $D D R 2$ 
mutations and in xenograft mouse models engrafted with $D D R 2$ mutant cell lines. ${ }^{147}$ In an early-phase clinical trial evaluating the role of dasatinib versus the combination of erlotinib and dasatinib in patients with advanced-stage lung cancer, one of the seven subjects with SQCC exhibited tumor shrinkage while undergoing therapy with erlotinib and dasatinib-a 59-year-old woman with a former smoking history of 11 pack-years. ${ }^{147}$ A subsequent molecular analysis of her pretreatment specimen demonstrated an S768R DDR2 kinase domain mutation, suggestive of a potentially targetable oncogenic driver; there is currently an ongoing phase 2 clinical trial evaluating the role of dasatinib in DDR2 mutant SQCC (NCT 01514864).

PI3K is a member of the lipid kinases and plays an important role in cell growth proliferation and survival. Aberrant activation of the PI3K pathway is associated with amplification or gain-of-function mutations of the PIK3CA gene, which encodes the catalytic subunit of class I PI3Ka, or loss of function of the PTEN tumor suppressor gene, a negative regulator of the PI3K pathway. ${ }^{148-150}$ Screening for PIK3CA mutations in several types of human cancer reveals an incidence of $~ 1.5 \%$ in NSCLC. ${ }^{151,152}$ In a series of 92 NSCLC tissues, PIK3CA amplification was found in 11 tissues (12\%), 2 of which also harbored PIK3CA mutations. ${ }^{153}$ PIK3CA copy number gains were more likely to occur in male smokers with squamous cell histology, and a PIK3CA copy number $\geq 3$ was associated with an inferior overall survival compared with a copy number $<3 .{ }^{153}$ The presence of PIK3CA mutations has been associated with inferior survival in SQCC of the lung and a predilection for brain metastases. ${ }^{154}$ In a series of 41 lung adenocarcinomas and 43 SQCC samples, PIK3CA amplification is found in 37\% SQCC and only 5\% of lung adenocarcinomas, mutations in $9 \%$ of SQCCs and $0 \%$ of adenocarcinomas, and loss of PTEN immunostaining in 21\% SQCCs and $4 \%$ of adenocarcinomas. ${ }^{155}$ Although $70 \%$ (16/23) of patients with PIK3CA mutant lung adenocarcinoma have coexisting oncogenic drivers (including $K R A S, M E K, B R A F, A L K$ rearrangements, and EGFR), PIK3CA mutations rarely occur with other oncogenic drivers in SQCC. ${ }^{113,142}$ Cell lines harboring pathway alterations are exquisitely sensitive to the PI3K inhibitor GDC-0941. ${ }^{155}$ This compound and other PI3K inhibitors are currently being studied in NSCLC with pathway alterations in PI3K in the context of phase 1 and 2 clinical trials (NCT 01297491; NCT 00974584).

\section{Conclusion}

In conclusion, the elucidation of oncogenic drivers in NSCLC has permanently shifted the landscape of NSCLC therapy to a personalized approach. Personalized NSCLC therapy necessitates a multidisciplinary approach to the issue of tissue acquisition and consideration of more invasive biopsy techniques to ensure there is adequate tissue both to distinguish histology and to perform molecular profiling. Adequate tissue acquisition at the time of diagnosis of metastatic disease is critical to identifying molecular subsets of patients in whom targeted therapy may be more effective than conventional chemotherapy; a paradigm exemplified by targeted TKI therapy in the EGFR mutant and the $A L K$ rearranged subsets of NSCLC. In addition, strong consideration should be given to a repeat biopsy at the time of progressive disease to better understand the mechanisms of resistance among these oncogenic drivers and to direct patients to clinical trials evaluating novel targeted therapies. 
While the story of personalized lung cancer therapy is most mature in EGFR mutant and $A L K$ rearranged NSCLC, there have been major advances in the last year in ROS1 rearranged and $B R A F$ mutant NSCLC. Comprehensive genotyping efforts have been successful in identifying an oncogenic driver in $62 \%$ of lung adenocarcinomas; the proportion of NSCLCs in which an oncogenic driver is identified will only increase with the incorporation of next generation sequencing into routine clinical practice. Although this is encouraging, it also highlights the ongoing need for the development of effective therapies for each of these NSCLC molecular subsets, the greatest priorities being the KRAS mutant lung adenocarcinoma subset and the molecular subsets of SQCC. Historically, NSCLC was treated as a single disease entity with limited response rates and guarded survival. Personalized NSCLC therapy has sculpted an evolving therapeutic landscape of highly effective therapies for molecular subsets of lung cancer.

\section{References}

1. Howlader, N.; Noone, AM.; Krapcho, M., et al. [Access date: October 31, 2013] SEER Stat Fact Sheets: Lung and Bronchus. 2010. http://seercancergov/csr/1975_2008/

2. Hopwood P, Stephens RJ. The Medical Research Council (MRC) Lung Cancer Working Party. Symptoms at presentation for treatment in patients with lung cancer: implications for the evaluation of palliative treatment. Br J Cancer. 1995; 71(3):633-636. [PubMed: 7533520]

3. Burdett S, Stephens R, Stewart L, et al. NSCLC Meta-Analyses Collaborative Group. Chemotherapy in addition to supportive care improves survival in advanced non-small-cell lung cancer: a systematic review and meta-analysis of individual patient data from 16 randomized controlled trials. J Clin Oncol. 2008; 26(28):4617-4625. [PubMed: 18678835]

4. Burdett S, Stewart L, Pignon J-P. Chemotherapy in non-small cell lung cancer: an update of an individual patient data-based meta-analysis. J Thorac Cardiovasc Surg. 2005; 129(5):1205. author reply 1205-1206. [PubMed: 15867822]

5. Rapp E, Pater JL, Willan A, et al. Chemotherapy can prolong survival in patients with advanced non-small-cell lung cancer - report of a Canadian multicenter randomized trial. J Clin Oncol. 1988; 6(4):633-641. [PubMed: 2833577]

6. Non-small Cell Lung Cancer Collaborative Group. Chemotherapy in non-small cell lung cancer: a meta-analysis using updated data on individual patients from 52 randomised clinical trials. BMJ. 1995; 311(7010):899-909. [PubMed: 7580546]

7. Fossella F, Pereira JR, von Pawel J, et al. Randomized, multinational, phase III study of docetaxel plus platinum combinations versus vinorelbine plus cisplatin for advanced non-small-cell lung cancer: the TAX 326 study group. J Clin Oncol. 2003; 21(16):3016-3024. [PubMed: 12837811]

8. Kelly K, Crowley J, Bunn PA Jr, et al. Randomized phase III trial of paclitaxel plus carboplatin versus vinorelbine plus cisplatin in the treatment of patients with advanced non-small-cell lung cancer: a Southwest Oncology Group trial. J Clin Oncol. 2001; 19(13):3210-3218. [PubMed: 11432888]

9. Scagliotti GV, De Marinis F, Rinaldi M. Italian Lung Cancer Project. Phase III randomized trial comparing three platinum-based doublets in advanced non-small-cell lung cancer. J Clin Oncol. 2002; 20(21):4285-4291. [PubMed: 12409326]

10. Schiller JH, Harrington D, Belani CP, et al. Eastern Cooperative Oncology Group. Comparison of four chemotherapy regimens for advanced non-small-cell lung cancer. N Engl J Med. 2002; 346(2):92-98. [PubMed: 11784875]

11. Zatloukal P, Petruzelka L, Zemanová M, et al. Gemcitabine plus cisplatin vs. gemcitabine plus carboplatin in stage IIIb and IV non-small cell lung cancer: a phase III randomized trial. Lung Cancer. 2003; 41(3):321-331. [PubMed: 12928123]

12. Lynch TJ, Bell DW, Sordella R, et al. Activating mutations in the epidermal growth factor receptor underlying responsiveness of non-small-cell lung cancer to gefitinib. N Engl J Med. 2004; 350(21):2129-2139. [PubMed: 15118073] 
13. Paez JG, Jänne PA, Lee JC, et al. EGFR mutations in lung cancer: correlation with clinical response to gefitinib therapy. Science. 2004; 304(5676):1497-1500. [PubMed: 15118125]

14. Kwak EL, Bang YJ, Camidge DR, et al. Anaplastic lymphoma kinase inhibition in non-small-cell lung cancer. N Engl J Med. 2010; 363(18):1693-1703. [PubMed: 20979469]

15. Bergethon K, Shaw AT, Ou SH, et al. ROS1 rearrangements define a unique molecular class of lung cancers. J Clin Oncol. 2012; 30(8):863-870. [PubMed: 22215748]

16. Ou SI, Bang Y, Camidge DR, et al. Efficacy and safety of crizotinib in patients with advanced ROS1-rearranged non-small cell lung cancer (NSCLC) [abstract]. J Clin Oncol. 2013; 31(15): 8032. ASCO Annual Meeting Proceedings (Post-Meeting Edition).

17. Dogan S, Shen R, Ang DC, et al. Molecular epidemiology of EGFR and KRAS mutations in 3,026 lung adenocarcinomas: higher susceptibility of women to smoking-related KRAS-mutant cancers. Clin Cancer Res. 2012; 18(22):6169-6177. [PubMed: 23014527]

18. Centers for Disease Control and Prevention (CDC). Annual smoking-attributable mortality, years of potential life lost, and productivity losses-United States, 1997-2001. MMWR Morb Mortal Wkly Rep. 2005; 54(25):625-628. [PubMed: 15988406]

19. Jemal A, Siegel R, Ward E, et al. Cancer statistics, 2008. CA Cancer J Clin. 2008; 58(2):71-96. [PubMed: 18287387]

20. Thun MJ, Henley SJ, Burns D, Jemal A, Shanks TG, Calle EE. Lung cancer death rates in lifelong nonsmokers. J Natl Cancer Inst. 2006; 98(10):691-699. [PubMed: 16705123]

21. Johnson BE, Kris MG, Berry LD, et al. A multicenter effort to identify driver mutations and employ targeted therapy in patients with lung adenocarcinomas: The Lung Cancer Mutation Consortium (LCMC) [abstract]. J Clin Oncol. 2013; 31(15):8019. ASCO Annual Meeting Proceedings (Post-Meeting Edition).

22. Herbst RS, Heymach JV, Lippman SM. Lung cancer. N Engl J Med. 2008; 359(13):1367-1380. [PubMed: 18815398]

23. Sharma SV, Bell DW, Settleman J, Haber DA. Epidermal growth factor receptor mutations in lung cancer. Nat Rev Cancer. 2007; 7(3):169-181. [PubMed: 17318210]

24. Mok TS, Wu YL, Thongprasert S, et al. Gefitinib or carboplatin-paclitaxel in pulmonary adenocarcinoma. N Engl J Med. 2009; 361(10):947-957. [PubMed: 19692680]

25. Rosell R, Carcereny E, Gervais R, et al. Spanish Lung Cancer Group in collaboration with Groupe Français de Pneumo-Cancérologie and Associazione Italiana Oncologia Toracica. Erlotinib versus standard chemotherapy as first-line treatment for European patients with advanced EGFR mutation-positive non-small-cell lung cancer (EURTAC): a multicentre, open-label, randomised phase 3 trial. Lancet Oncol. 2012; 13(3):239-246. [PubMed: 22285168]

26. Zhou C, Wu YL, Chen G, et al. Erlotinib versus chemotherapy as first-line treatment for patients with advanced EGFR mutation-positive non-small-cell lung cancer (OPTIMAL, CTONG-0802): a multicentre, open-label, randomised, phase 3 study. Lancet Oncol. 2011; 12(8):735-742. [PubMed: 21783417]

27. Maemondo M, Inoue A, Kobayashi K, et al. North-East Japan Study Group. Gefitinib or chemotherapy for non-small-cell lung cancer with mutated EGFR. N Engl J Med. 2010; 362(25): 2380-2388. [PubMed: 20573926]

28. Mitsudomi T, Morita S, Yatabe Y, et al. West Japan Oncology Group. Gefitinib versus cisplatin plus docetaxel in patients with non-small-cell lung cancer harbouring mutations of the epidermal growth factor receptor (WJTOG3405): an open label, randomised phase 3 trial. Lancet Oncol. 2010; 11(2):121-128. [PubMed: 20022809]

29. Sequist LV, Yang JC, Yamamoto N, et al. Phase III study of afatinib or cisplatin plus pemetrexed in patients with metastatic lung adenocarcinoma with EGFR mutations. J Clin Oncol. 2013; 31(27): 3327-3334. [PubMed: 23816960]

30. Wu YL, Zhou C, Hu C, et al. LUX-Lung 6: A randomized, open-label, phase III study of afatinab (A) versus gemcitabine/cisplatin (GC) as first-line treatment for Asian patients (pts) with EGFR mutation-positive (EGFR M+) advanced adenocarcinoma of the lung [abstract]. J Clin Oncol. 2013; 31(15):8016. ASCO Annual Meeting Proceedings (Post-Meeting Edition).

31. Fukuoka M, Wu YL, Thongprasert S, et al. Biomarker analyses and final overall survival results from a phase III, randomized, open-label, first-line study of gefitinib versus carboplatin/ paclitaxel 
in clinically selected patients with advanced non-small-cell lung cancer in Asia (IPASS). J Clin Oncol. 2011; 29(21):2866-2874. [PubMed: 21670455]

32. Mok T, Yang JJ, Lam KC. Treating patients with EGFR-sensitizing mutations: first line or second line-is there a difference? J Clin Oncol. 2013; 31(8):1081-1088. [PubMed: 23401448]

33. Arcila ME, Oxnard GR, Nafa K, et al. Rebiopsy of lung cancer patients with acquired resistance to EGFR inhibitors and enhanced detection of the T790M mutation using a locked nucleic acid-based assay. Clin Cancer Res. 2011; 17(5):1169-1180. [PubMed: 21248300]

34. Yu HA, Arcila ME, Rekhtman N, et al. Analysis of tumor specimens at the time of acquired resistance to EGFR-TKI therapy in 155 patients with EGFR-mutant lung cancers. Clin Cancer Res. 2013; 19(8):2240-2247. [PubMed: 23470965]

35. Miller VA, Hirsh V, Cadranel J, et al. Afatinib versus placebo for patients with advanced, metastatic non-small-cell lung cancer after failure of erlotinib, gefitinib, or both, and one or two lines of chemotherapy (LUX-Lung 1): a phase 2b/3 randomised trial. Lancet Oncol. 2012; 13(5): 528-538. [PubMed: 22452896]

36. Regales L, Gong Y, Shen R, et al. Dual targeting of EGFR can overcome a major drug resistance mutation in mouse models of EGFR mutant lung cancer. J Clin Invest. 2009; 119(10):3000-3010. [PubMed: 19759520]

37. Takezawa K, Pirazzoli V, Arcila ME, et al. HER2 amplification: a potential mechanism of acquired resistance to EGFR inhibition in EGFR-mutant lung cancers that lack the second-site EGFRT790M mutation. Cancer Discov. 2012; 2(10):922-933. [PubMed: 22956644]

38. Ohashi K, Sequist LV, Arcila ME, et al. Lung cancers with acquired resistance to EGFR inhibitors occasionally harbor BRAF gene mutations but lack mutations in KRAS, NRAS, or MEK1. Proc Natl Acad Sci U S A. 2012; 109(31):E2127-E2133. [PubMed: 22773810]

39. Sequist LV, Waltman BA, Dias-Santagata D, et al. Genotypic and histological evolution of lung cancers acquiring resistance to EGFR inhibitors. Sci Transl Med. 2011; 3(75):75ra26.

40. Bean J, Brennan C, Shih JY, et al. MET amplification occurs with or without T790M mutations in EGFR mutant lung tumors with acquired resistance to gefitinib or erlotinib. Proc Natl Acad Sci U S A. 2007; 104(52):20932-20937. [PubMed: 18093943]

41. Engelman JA, Zejnullahu K, Mitsudomi T, et al. MET amplification leads to gefitinib resistance in lung cancer by activating ERBB3 signaling. Science. 2007; 316(5827):1039-1043. [PubMed: 17463250]

42. Chiarle R, Voena C, Ambrogio C, Piva R, Inghirami G. The anaplastic lymphoma kinase in the pathogenesis of cancer. Nat Rev Cancer. 2008; 8(1):11-23. [PubMed: 18097461]

43. Soda M, Choi YL, Enomoto M, et al. Identification of the transforming EML4-ALK fusion gene in non-small-cell lung cancer. Nature. 2007; 448(7153):561-566. [PubMed: 17625570]

44. Horn L, Pao W. EML4-ALK: honing in on a new target in non-small-cell lung cancer. J Clin Oncol. 2009; 27(26):4232-4235. [PubMed: 19667260]

45. Chen Z, Sasaki T, Tan X, et al. Inhibition of ALK, PI3K/MEK, and HSP90 in murine lung adenocarcinoma induced by EML4-ALK fusion oncogene. Cancer Res. 2010; 70(23):9827-9836. [PubMed: 20952506]

46. McDermott U, Iafrate AJ, Gray NS, et al. Genomic alterations of anaplastic lymphoma kinase may sensitize tumors to anaplastic lymphoma kinase inhibitors. Cancer Res. 2008; 68(9):3389-3395. [PubMed: 18451166]

47. Soda M, Takada S, Takeuchi K, et al. A mouse model for EML4-ALK-positive lung cancer. Proc Natl Acad Sci U S A. 2008; 105(50):19893-19897. [PubMed: 19064915]

48. Shaw AT, Yeap BY, Mino-Kenudson M, et al. Clinical features and outcome of patients with nonsmall-cell lung cancer who harbor EML4-ALK. J Clin Oncol. 2009; 27(26):4247-4253. [PubMed: 19667264]

49. Wong DW, Leung EL, So KK, et al. University of Hong Kong Lung Cancer Study Group. The EML4-ALK fusion gene is involved in various histologic types of lung cancers from nonsmokers with wild-type EGFR and KRAS. Cancer. 2009; 115(8):1723-1733. [PubMed: 19170230]

50. Camidge DR, Bang YJ, Kwak EL, et al. Activity and safety of crizotinib in patients with ALKpositive non-small-cell lung cancer: updated results from a phase 1 study. Lancet Oncol. 2012; 13(10):1011-1019. [PubMed: 22954507] 
51. Kim DW, Ahn MJ, Shi Y. Results of a global phase II study with crizotinib in advanced ALKpositive non-small cell lung cancer [abstract]. J Clin Oncol. 2012; 30(15):7533. ASCO Annual Meeting Proceedings (Post-Meeting Edition).

52. Shaw AT, Yeap BY, Solomon BJ, et al. Effect of crizotinib on overall survival in patients with advanced non-small-cell lung cancer harbouring ALK gene rearrangement: a retrospective analysis. Lancet Oncol. 2011; 12(11):1004-1012. [PubMed: 21933749]

53. Shaw AT, Kim DW, Nakagawa K, et al. Crizotinib versus chemotherapy in advanced ALK-positive lung cancer. N Engl J Med. 2013; 368(25):2385-2394. [PubMed: 23724913]

54. Choi YL, Soda M, Yamashita Y, et al. ALK Lung Cancer Study Group. EML4-ALK mutations in lung cancer that confer resistance to ALK inhibitors. N Engl J Med. 2010; 363(18):1734-1739. [PubMed: 20979473]

55. Katayama R, Khan TM, Benes C, et al. Therapeutic strategies to overcome crizotinib resistance in non-small cell lung cancers harboring the fusion oncogene EML4-ALK. Proc Natl Acad Sci U S A. 2011; 108(18):7535-7540. [PubMed: 21502504]

56. Lovly CM, Pao W. Escaping ALK inhibition: mechanisms of and strategies to overcome resistance. Sci Transl Med. 2012; 4(120):ps2.

57. Doebele RC, Pilling AB, Aisner DL, et al. Mechanisms of resistance to crizotinib in patients with ALK gene rearranged non-small cell lung cancer. Clin Cancer Res. 2012; 18(5):1472-1482. [PubMed: 22235099]

58. Katayama R, Shaw AT, Khan TM, et al. Mechanisms of acquired crizotinib resistance in ALKrearranged lung Cancers. Sci Transl Med. 2012; 4(120):20ra17.

59. Sasaki T, Koivunen J, Ogino A, et al. A novel ALK secondary mutation and EGFR signaling cause resistance to ALK kinase inhibitors. Cancer Res. 2011; 71(18):6051-6060. [PubMed: 21791641]

60. Shaw AT, Mehra R, Kim DW, et al. Clinical activity of the ALK inhibitor LDK378 in advanced, ALK-positive NSCLC [abstract]. J Clin Oncol. 2013; 31(15):8010. ASCO Annual Meeting Proceedings (Post-Meeting Edition).

61. Nakagawa K, Kiura K, Nishio M, et al. A phase I/II study with a highly selective ALK inhibitor CH5424802 in ALK-positive non-small cell lung cancer (NSCLC) patients: Updated safety and efficacy results from AF-001JP [abstract]. J Clin Oncol. 2013; 31(15):8033. ASCO Annual Meeting Proceedings (Post-Meeting Edition).

62. Socinski MA, Goldman J, El-Hariry I, et al. A multicenter phase II study of ganetespib monotherapy in patients with genotypically defined advanced non-small cell lung cancer. Clin Cancer Res. 2013; 19(11):3068-3077. [PubMed: 23553849]

63. Garon EB, Moran T, Barlesi F, et al. Phase II study of the HSP90 inhibitor AUY922 in patients with previously treated, advanced non-small cell lung cancer (NSCLC) [abstract]. J Clin Oncol. 2012; 30(15):7543. ASCO Annual Meeting Proceedings (Post-Meeting Edition).

64. Sequist LV, Gettinger S, Senzer NN, et al. Activity of IPI-504, a novel heat-shock protein 90 inhibitor, in patients with molecularly defined non-small-cell lung cancer. J Clin Oncol. 2010; 28(33):4953-4960. [PubMed: 20940188]

65. Ou SH, Tan J, Yen Y, Soo RA. ROS1 as a 'druggable' receptor tyrosine kinase:lessons learned from inhibiting the ALK pathway. Expert Rev Anticancer Ther. 2012; 12(4):447-456. [PubMed: 22500682]

66. Shaw AT, Camidge DR, Engelman JA, et al. Clinical activity of crizotinib in advanced non-small cell lung cancer (NSCLC) harboring ROS1 gene rearrangement [abstract]. J Clin Oncol. 2012; 30(15):7508. ASCO Annual Meeting Proceedings (Post-Meeting Edition).

67. Birchmeier C, O'Neill K, Riggs M, Wigler M. Characterization of ROS1 cDNA from a human glioblastoma cell line. Proc Natl Acad Sci U S A. 1990; 87(12):4799-4803. [PubMed: 2352949]

68. Birchmeier C, Sharma S, Wigler M. Expression and rearrangement of the ROS1 gene in human glioblastoma cells. Proc Natl Acad Sci U S A. 1987; 84(24):9270-9274. [PubMed: 2827175]

69. Charest A, Lane K, McMahon K, et al. Fusion of FIG to the receptor tyrosine kinase ROS in a glioblastoma with an interstitial del(6) (q21q21). Genes Chromosomes Cancer. 2003; 37(1):58-71. [PubMed: 12661006] 
70. Charest A, Wilker EW, McLaughlin ME, et al. ROS fusion tyrosine kinase activates a SH2 domaincontaining phosphatase-2/phosphatidylinositol 3-kinase/mammalian target of rapamycin signaling axis to form glioblastoma in mice. Cancer Res. 2006; 66(15):7473-7481. [PubMed: 16885344]

71. Chin LP, Soo RA, Soong R, Ou SH. Targeting ROS1 with anaplastic lymphoma kinase inhibitors: a promising therapeutic strategy for a newly defined molecular subset of non-small-cell lung cancer. J Thorac Oncol. 2012; 7(11):1625-1630. [PubMed: 23070242]

72. Takeuchi K, Soda M, Togashi Y, et al. RET, ROS1 and ALK fusions in lung cancer. Nat Med. 2012; 18(3):378-381. [PubMed: 22327623]

73. Rimkunas VM, Crosby KE, Li D, et al. Analysis of receptor tyrosine kinase ROS1-positive tumors in non-small cell lung cancer: identification of a FIG-ROS1 fusion. Clin Cancer Res. 2012; 18(16): 4449-4457. [PubMed: 22661537]

74. Davies H, Bignell GR, Cox C, et al. Mutations of the BRAF gene in human cancer. Nature. 2002; 417(6892):949-954. [PubMed: 12068308]

75. Tol J, Nagtegaal ID, Punt CJA. BRAF mutation in metastatic colorectal cancer. N Engl J Med. 2009; 361(1):98-99. [PubMed: 19571295]

76. De Roock W, Claes B, Bernasconi D, et al. Effects of KRAS, BRAF, NRAS, and PIK3CA mutations on the efficacy of cetuximab plus chemotherapy in chemotherapy-refractory metastatic colorectal cancer: a retrospective consortium analysis. Lancet Oncol. 2010; 11(8):753-762. [PubMed: 20619739]

77. Paik PK, Arcila ME, Fara M, et al. Clinical characteristics of patients with lung adenocarcinomas harboring BRAF mutations. J Clin Oncol. 2011; 29(15):2046-2051. [PubMed: 21483012]

78. Bollag G, Tsai J, Zhang J, et al. Vemurafenib: the first drug approved for BRAF-mutant cancer. Nat Rev Drug Discov. 2012; 11(11):873-886. [PubMed: 23060265]

79. Gautschi O, Pauli C, Strobel K, et al. A patient with BRAF V600E lung adenocarcinoma responding to vemurafenib. J Thorac Oncol. 2012; 7(10):e23-e24. [PubMed: 22743296]

80. Peters S, Michielin O, Zimmermann S. Dramatic response induced by vemurafenib in a BRAF V600E-mutated lung adenocarcinoma. J Clin Oncol. 2013; 31(20):e341-e344. [Epub ahead of print]. [PubMed: 23733758]

81. Planchard D, Mazieres J, Riely GJ, et al. Interim results of phase II study BRF113928 of dabrafenibin BRAF V600E mutation-positive non-small cell lung cancer (NSCLC) patients. J Clin Oncol. 2013; 31(15):8009. ASCO Annual Meeting Proceedings (Post-Meeting Edition).

82. Rudin CM, Hong K, Streit M. Molecular characterization of acquired resistance to the BRAF inhibitor dabrafenib in a patient with BRAF-mutant non-small-cell lung cancer. J Thorac Oncol. 2013; 8(5):e41-e42. [PubMed: 23524406]

83. Pao W, Girard N. New driver mutations in non-small-cell lung cancer. Lancet Oncol. 2011; 12(2): 175-180. [PubMed: 21277552]

84. Gherardi E, Birchmeier W, Birchmeier C, Vande Woude G. Targeting MET in cancer: rationale and progress. Nat Rev Cancer. 2012; 12(2):89-103. [PubMed: 22270953]

85. Sadiq AA, Salgia R. MET as a possible target for non-small-cell lung cancer. J Clin Oncol. 2013; 31(8):1089-1096. [PubMed: 23401458]

86. Ma PC, Jagadeeswaran R, Jagadeesh S, et al. Functional expression and mutations of c-Met and its therapeutic inhibition with SU11274 and small interfering RNA in non-small cell lung cancer. Cancer Res. 2005; 65(4):1479-1488. [PubMed: 15735036]

87. Beau-Faller M, Ruppert AM, Voegeli AC, et al. MET gene copy number in non-small cell lung cancer: molecular analysis in a targeted tyrosine kinase inhibitor naïve cohort. J Thorac Oncol. 2008; 3(4):331-339. [PubMed: 18379349]

88. Onitsuka T, Uramoto H, Ono K, et al. Comprehensive molecular analyses of lung adenocarcinoma with regard to the epidermal growth factor receptor, K-ras, MET, and hepatocyte growth factor status. J Thorac Oncol. 2010; 5(5):591-596. [PubMed: 20150826]

89. Onozato R, Kosaka T, Kuwano H, Sekido Y, Yatabe Y, Mitsudomi T. Activation of MET by gene amplification or by splice mutations deleting the juxtamembrane domain in primary resected lung cancers. J Thorac Oncol. 2009; 4(1):5-11. [PubMed: 19096300]

90. Spigel DR, Ervin TJ, Ramlau R, et al. Final efficacy results from OAM4558g, a randomized phase II study evaluating MetMAb or placebo in combination with erlotinib in advanced NSCLC 
[abstract]. J Clin Oncol. 2011; 29(15):7505. ASCO Annual Meeting Proceedings (Post-Meeting Edition).

91. Peters S, Adjei AA. MET: a promising anticancer therapeutic target. Nat Rev Clin Oncol. 2012; 9(6):314-326. [PubMed: 22566105]

92. Ou SH, Kwak EL, Siwak-Tapp C, et al. Activity of crizotinib (PF02341066), a dual mesenchymalepithelial transition (MET) and anaplastic lymphoma kinase (ALK) inhibitor, in a non-small cell lung cancer patient with de novo MET amplification. J Thorac Oncol. 2011; 6(5):942-946. [PubMed: 21623265]

93. Chi AS, Batchelor TT, Kwak EL, et al. Rapid radiographic and clinical improvement after treatment of a MET-amplified recurrent glioblastoma with a mesenchymal-epithelial transition inhibitor. J Clin Oncol. 2012; 30(3):e30-e33. [PubMed: 22162573]

94. Eng C. RET proto-oncogene in the development of human cancer. J Clin Oncol. 1999; 17(1):380393. [PubMed: 10458257]

95. Phay JE, Shah MH. Targeting RET receptor tyrosine kinase activation in cancer. Clin Cancer Res. 2010; 16(24):5936-5941. [PubMed: 20930041]

96. Blaugrund JE, Johns MM Jr, Eby YJ, et al. RET proto-oncogene mutations in inherited and sporadic medullary thyroid cancer. Hum Mol Genet. 1994; 3(10):1895-1897. [PubMed: 7849720]

97. Grieco M, Santoro M, Berlingieri MT, et al. PTC is a novel rearranged form of the ret protooncogene and is frequently detected in vivo in human thyroid papillary carcinomas. Cell. 1990; 60(4):557-563. [PubMed: 2406025]

98. Santoro M, Dathan NA, Berlingieri MT, et al. Molecular characterization of RET/PTC3; a novel rearranged version of the RETproto-oncogene in a human thyroid papillary carcinoma. Oncogene. 1994; 9(2):509-516. [PubMed: 8290261]

99. Nikiforov YE, Nikiforova MN. Molecular genetics and diagnosis of thyroid cancer. Nat Rev Endocrinol. 2011; 7(10):569-580. [PubMed: 21878896]

100. Wells SA Jr, Santoro M. Targeting the RET pathway in thyroid cancer. Clin Cancer Res. 2009; 15(23):7119-7123. [PubMed: 19934298]

101. Jhiang SM. The RET proto-oncogene in human cancers. Oncogene. 2000; 19(49):5590-5597. [PubMed: 11114739]

102. Takeuchi K, Choi YL, Togashi Y, et al. KIF5B-ALK, a novel fusion oncokinase identified by an immunohistochemistry-based diagnostic system for ALK-positive lung cancer. Clin Cancer Res. 2009; 15(9):3143-3149. [PubMed: 19383809]

103. Kohno T, Ichikawa H, Totoki Y, et al. KIF5B-RET fusions in lung adenocarcinoma. Nat Med. 2012; 18(3):375-377. [PubMed: 22327624]

104. Wang R, Hu H, Pan Y, et al. RET fusions define a unique molecular and clinicopathologic subtype of non-small-cell lung cancer. J Clin Oncol. 2012; 30(35):4352-4359. [PubMed: 23150706]

105. Gautschi O, Zander T, Keller FA, et al. A patient with lung adenocarcinoma and RET fusion treated with vandetanib. J Thorac Oncol. 2013; 8(5):e43-e44. [PubMed: 23584301]

106. Spector NL, Blackwell KL. Understanding the mechanisms behind trastuzumab therapy for human epidermal growth factor receptor 2-positive breast cancer. J Clin Oncol. 2009; 27(34): 5838-5847. [PubMed: 19884552]

107. Stephens P, Hunter C, Bignell G, et al. Lung cancer: intragenic ERBB2 kinase mutations in tumours. Nature. 2004; 431(7008):525-526. [PubMed: 15457249]

108. Gatzemeier U, Groth G, Butts C, et al. Randomized phase II trial of gemcitabine-cisplatin with or without trastuzumab in HER2-positive non-small-cell lung cancer. Ann Oncol. 2004; 15(1):1927. [PubMed: 14679114]

109. Arcila ME, Chaft JE, Nafa K, et al. Prevalence, clinicopathologic associations, and molecular spectrum of ERBB2 (HER2) tyrosine kinase mutations in lung adenocarcinomas. ClinCancer Res. 2012; 18(18):4910-4918.

110. Shigematsu H, Takahashi T, Nomura M, et al. Somatic mutations of the HER2 kinase domain in lung adenocarcinomas. Cancer Res. 2005; 65(5):1642-1646. [PubMed: 15753357] 
111. Tomizawa K, Suda K, Onozato R, et al. Prognostic and predictive implications of HER2/ ERBB2/neu gene mutations in lung cancers. Lung Cancer. 2011; 74(1):139-144. [PubMed: 21353324]

112. Mazières J, Peters $S$, Lepage $B$, et al. Lung cancer that harbors an HER2 mutation: epidemiologic characteristics and therapeutic perspectives. J Clin Oncol. 2013; 31(16):1997-2003. [PubMed: 23610105]

113. Chaft JE, Arcila ME, Paik PK, et al. Coexistence of PIK3CA and other oncogene mutations in lung adenocarcinoma-rationale for comprehensive mutation profiling. Mol Cancer Ther. 2012; 11(2):485-491. [PubMed: 22135231]

114. Bendell JC, Rodon J, Burris HA, et al. Phase I, dose-escalation study of BKM120, an oral panClass I PI3K inhibitor, in patients with advanced solid tumors. J Clin Oncol. 2012; 30(3):282290. [PubMed: 22162589]

115. Shapiro G, Kwak EL, Baselga J, et al. Phase I dose-escalation study of XL147, a PI3K inhibitor administered orally to patients with solid tumors [abstract]. J Clin Oncol. 2009; 27(15S):3500. ASCO Annual Meeting Proceedings (Post-Meeting Edition).

116. Ding L, Getz G, Wheeler DA, et al. Somatic mutations affect key pathways in lung adenocarcinoma. Nature. 2008; 455(7216):1069-1075. [PubMed: 18948947]

117. Malanga D, Scrima M, De Marco C, et al. Activating E17K mutation in the gene encoding the protein kinase AKT1 in a subset of squamous cell carcinoma of the lung. Cell Cycle. 2008; 7(5): 665-669. [PubMed: 18256540]

118. Yap TA, Yan L, Patnaik A, et al. First-in-man clinical trial of the oral pan-AKT inhibitor MK-2206 in patients with advanced solid tumors. J Clin Oncol. 2011; 29(35):4688-4695. [PubMed: 22025163]

119. Marks JL, Gong Y, Chitale D, et al. Novel MEK1 mutation identified by mutational analysis of epidermal growth factor receptor signaling pathway genes in lung adenocarcinoma. Cancer Res. 2008; 68(14):5524-5528. [PubMed: 18632602]

120. Jänne PA, Shaw AT, Pereira JR, et al. Selumetinib plus docetaxel for KRAS-mutant advanced non-small-cell lung cancer: a randomised, multicentre, placebo-controlled, phase 2 study. Lancet Oncol. 2013; 14(1):38-47. [PubMed: 23200175]

121. Gandara D, Hiret S, Blumenschein GR, et al. Oral MEK1/MEK2 inhibitor trametinib (GSK1120212) in combination with docetaxel in KRAS-mutant and wild-type (WT) advanced non-small cell lung cancer (NSCLC): A phase I/Ib trial [abstract]. J Clin Oncol. 2013; 31(15): 8028. ASCO Annual Meeting Proceedings (Post-Meeting Edition).

122. Becerra C, Infante JR, Garbo LE, et al. A five-arm, open-label, phase I/Ib study to access safety and tolerability of the oral MEK1/MEK2 inhibitor trametinib(GSK1120212) in combination with chemotherapy or erlotinib in patients with advanced solid tumors [abstract]. J Clin Oncol. 2012; 30(15):3023. ASCO Annual Meeting Proceedings (Post-Meeting Edition).

123. Doebele RC, Vaishnavi A, Capelletti M, et al. NTRK1 gene fusions as a novel oncogene target in lung cancer [abstract]. J Clin Oncol. 2013; 31(15):8023. ASCO Annual Meeting Proceedings (Post-Meeting Edition).

124. Mo ML, Chen Z, Zhou HM, et al. Detection of E2A-PBX1 fusion transcripts in human nonsmall-cell lung cancer. J Exp Clin Cancer Res. 2013; 32:29. [PubMed: 23688269]

125. Bicocca VT, Chang BH, Masouleh BK, et al. Crosstalk between ROR1 and the Pre-B cell receptor promotes survival of $\mathrm{t}(1 ; 19)$ acute lymphoblastic leukemia. Cancer Cell. 2012; 22(5): 656-667. [PubMed: 23153538]

126. Karnoub AE, Weinberg RA. Ras oncogenes: split personalities. Nat Rev Mol Cell Biol. 2008; 9(7):517-531. [PubMed: 18568040]

127. Nakano H, Yamamoto F, Neville C, Evans D, Mizuno T, Perucho M. Isolation of transforming sequences of two human lung carcinomas: structural and functional analysis of the activated c-Kras oncogenes. Proc Natl Acad Sci U S A. 1984; 81(1):71-75. [PubMed: 6320174]

128. Santos E, Martin-Zanca D, Reddy EP, Pierotti MA, Della Porta G, Barbacid M. Malignant activation of a K-ras oncogene in lung carcinoma but not in normal tissue of the same patient. Science. 1984; 223(4637):661-664. [PubMed: 6695174] 
129. Riely GJ, Marks J, Pao W. KRAS mutations in non-small cell lung cancer. Proc Am Thorac Soc. 2009; 6(2):201-205. [PubMed: 19349489]

130. Mascaux C, Iannino N, Martin B, et al. The role of RAS oncogene in survival of patients with lung cancer: a systematic review of the literature with meta-analysis. Br J Cancer. 2005; 92(1): 131-139. [PubMed: 15597105]

131. Riely GJ, Kris MG, Rosenbaum D, et al. Frequency and distinctive spectrum of KRAS mutations in never smokers with lung adenocarcinoma. Clin Cancer Res. 2008; 14(18):5731-5734. [PubMed: 18794081]

132. Ihle NT, Byers LA, Kim ES, et al. Effect of KRAS oncogene substitutions on protein behavior: implications for signaling and clinical outcome. J Natl Cancer Inst. 2012; 104(3):228-239. [PubMed: 22247021]

133. Villaruz LC, Socinski MA, Cunningham DE, et al. The prognostic and predictive value of KRAS oncogene substitutions in lung adenocarcinoma. Cancer. 2013; 119(12):2268-2274. [PubMed: 23526491]

134. Yu HA, Sima CS, Shen R, et al. Comparison of the characteristics and clinical course of 677 patients with metastatic lung cancers with mutations in KRAS codons 12 and 13 [abstract]. J Clin Oncol. 2013; 31(15):8025. ASCO Annual Meeting Proceedings (Post-Meeting Edition).

135. Jänne PA, Shaw AT, Pereira JR, et al. Selumetinib plus docetaxel for KRAS-mutant advanced non-small-cell lung cancer: a randomised, multicentre, placebo-controlled, phase 2 study. Lancet Oncol. 2013; 14(1):38-47. [PubMed: 23200175]

136. Sequist LV, von Pawel J, Garmey EG, et al. Randomized phase II study of erlotinib plus tivantinib versus erlotinib plus placebo in previously treated non-small-cell lung cancer. J Clin Oncol. 2011; 29(24):3307-3315. [PubMed: 21768463]

137. Acquaviva J, Smith DL, Sang J, et al. Targeting KRAS-mutant non-small cell lung cancer with the Hsp90 inhibitor ganetespib. Mol Cancer Ther. 2012; 11(12):2633-2643. [PubMed: 23012248]

138. De Raedt T, Walton Z, Yecies JL, et al. Exploiting cancer cell vulnerabilities to develop a combination therapy for ras-driven tumors. Cancer Cell. 2011; 20(3):400-413. [PubMed: 21907929]

139. O’Byrne KJ, Bondarenko I, Barrios C, et al. Molecular and clinical predictors of outcome for cetuximabin non-small cell lung cancer (NSCLC): Data from the FLEX study [abstract]. ASCO Meeting Abstracts 2009. J Clin Oncol. 2009; 27(15S):8007. ASCO Annual Meeting Proceedings (Post-Meeting Edition).

140. Fennell DA, Goss GD, Socinski MA, et al. GALAXY-2 trial: A randomized phase III study of ganetespib in combination with docetaxel versus docetaxel alone in patients with advanced nonsmall celllung adenocarcinoma[abstract]. J Clin Oncol. 2013; 31(15):TPS8126. ASCO Annual Meeting Proceedings (Post-Meeting Edition).

141. Riely GJ, Brahmer JR, Planchard D, et al. A randomzied discontinuation phase II trial of ridaforolimus in non-small cell lung cancer (NSCLC) patients with KRAS mutations [abstract]. J Clin Oncol. 2012; 30(15):7531. ASCO Annual Meeting Proceedings (Post-Meeting Edition).

142. Rekhtman N, Paik PK, Arcila ME, et al. Clarifying the spectrum of driver oncogene mutations in biomarker-verified squamous carcinoma of lung: lack of EGFR/KRAS and presence of PIK3CA/ AKT1 mutations. Clin Cancer Res. 2012; 18(4):1167-1176. [PubMed: 22228640]

143. Genome Atlas Research Network. Comprehensive genomic characterization of squamous cell lung cancers. Nature. 2012; 489(7417):519-525. [PubMed: 22960745]

144. Weiss J, Sos ML, Seidel D, et al. Frequent and focal FGFR1 amplification associates with therapeutically tractable FGFR1 dependency in squamous cell lung cancer. Sci Transl Med. 2010; 2(62):62ra93.

145. Dutt A, Ramos AH, Hammerman PS, et al. Inhibitor-sensitive FGFR1 amplification in human non-small cell lung cancer. PLoS ONE. 2011; 6(6):e20351. [PubMed: 21666749]

146. Ratain MJ, Schwartz GK, Oza AM, et al. Brivanib (BMS-582664) in advanced solid tumors (AST): Results of a phase II randomized discontinuation trial (RDT) [abstract]. J Clin Oncol. 2011; 29(15):3079. ASCO Annual Meeting Proceedings (Post-Meeting Edition). 
147. Hammerman PS, Sos ML, Ramos AH, et al. Mutations in the DDR2 kinase gene identify a novel therapeutic target in squamous cell lung cancer. Cancer Discov. 2011; 1(1):78-89. [PubMed: 22328973]

148. Shayesteh L, Lu Y, Kuo WL, et al. PIK3CA is implicated as an oncogene in ovarian cancer. Nat Genet. 1999; 21(1):99-102. [PubMed: 9916799]

149. Samuels Y, Wang Z, Bardelli A, et al. High frequency of mutations of the PIK3CA gene in human cancers. Science. 2004; 304(5670):554. [PubMed: 15016963]

150. Sansal I, Sellers WR. The biology and clinical relevance of the PTEN tumor suppressor pathway. J Clin Oncol. 2004; 22(14):2954-2963. [PubMed: 15254063]

151. Lee JW, Soung YH, Kim SY, et al. PIK3CA gene is frequently mutated in breast carcinomas and hepatocellular carcinomas. Oncogene. 2005; 24(8):1477-1480. [PubMed: 15608678]

152. Yamamoto H, Shigematsu H, Nomura M, et al. PIK3CA mutations and copy number gains in human lung cancers. Cancer Res. 2008; 68(17):6913-6921. [PubMed: 18757405]

153. Kawano O, Sasaki H, Okuda K, et al. PIK3CA gene amplification in Japanese non-small cell lung cancer. Lung Cancer. 2007; 58(1):159-160. [PubMed: 17681398]

154. Paik PK, Moreira AL, Wang L, et al. Patterns of metastasis and survival in patients with PI3K pathway-driven stage IV squamous cell lung cancers (SQCLC). J Clin Oncol. 2013; 31(15):8022. ASCO Annual Meeting Proceedings (Post-Meeting Edition).

155. Spoerke JM, O’Brien C, Huw L, et al. Phosphoinositide 3-kinase (PI3K) pathway alterations are associated with histologic subtypes and are predictive of sensitivity to PI3K inhibitors in lung cancer preclinical models. Clin Cancer Res. 2012; 18(24):6771-6783. [PubMed: 23136191]

156. Han JY, Park K, Kim SW, et al. First-SIGNAL: first-line single-agent iressa versus gemcitabine and cisplatin trial in never-smokers with adenocarcinoma of the lung. J Clin Oncol. 2012; 30(10): 1122-1128. [PubMed: 22370314] 


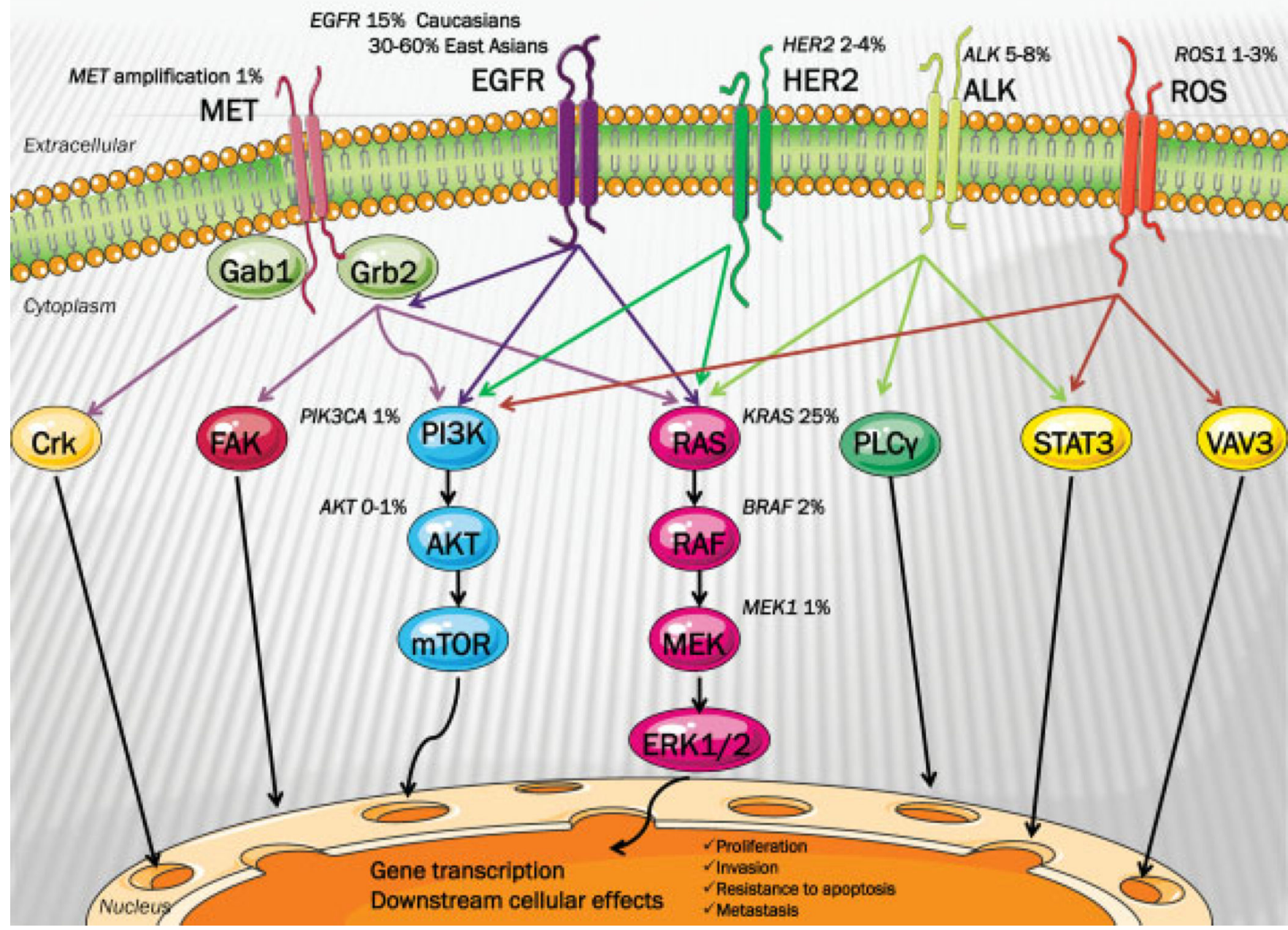

Fig. 1.

Key signaling pathways in non-small cell lung cancer and the frequency of oncogenic driver mutations and gene rearrangements in adenocarcinoma of the lung. 


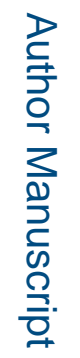

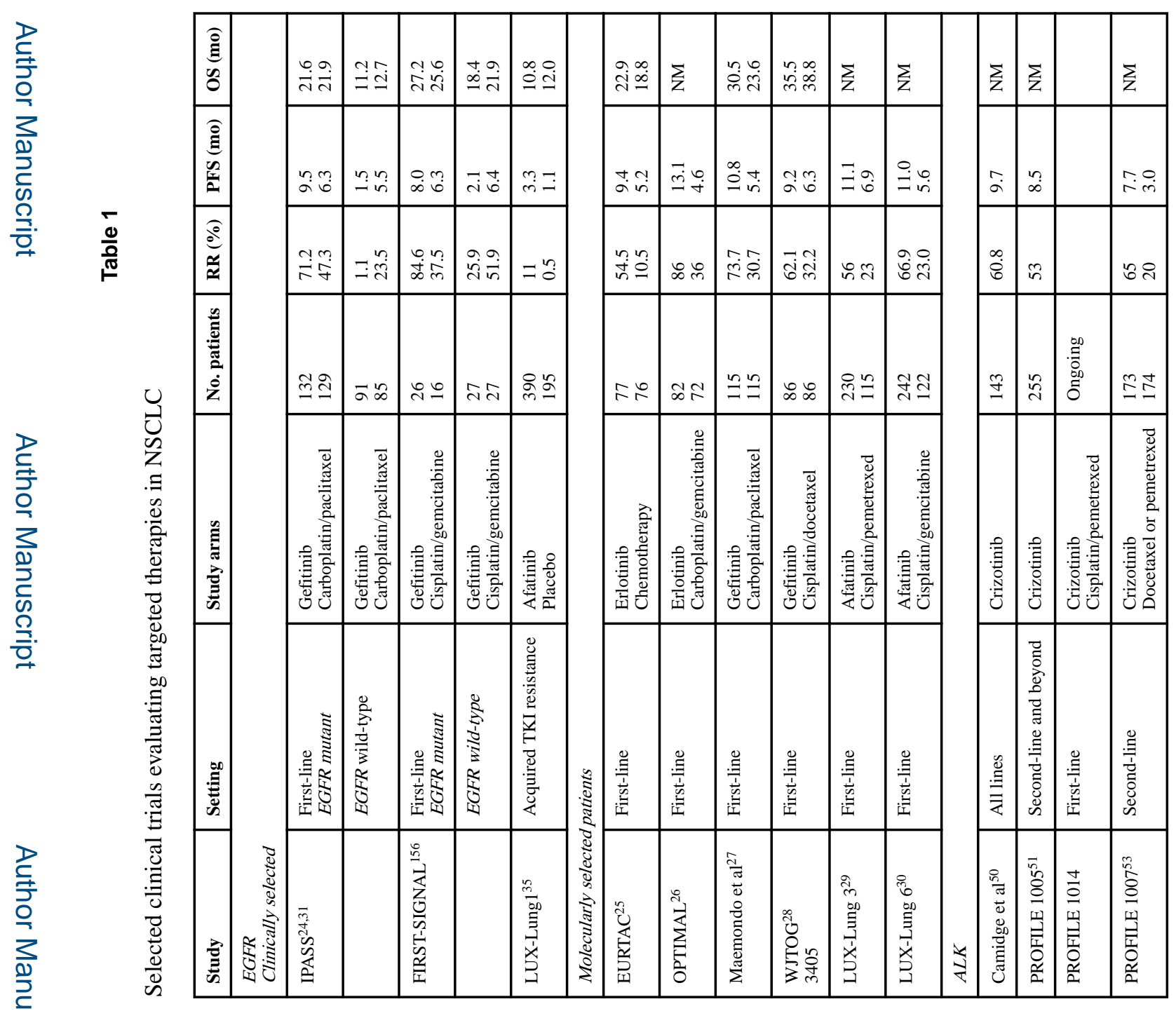

Semin Respir Crit Care Med. Author manuscript; available in PMC 2016 April 19. 


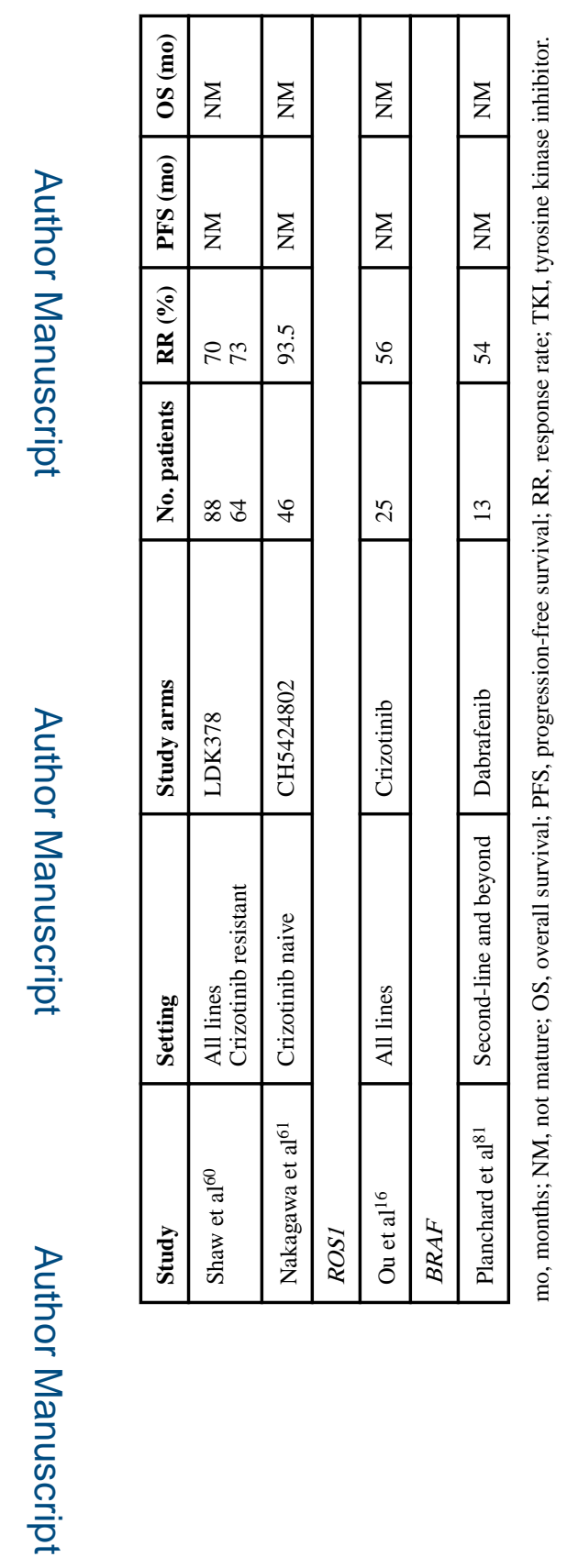

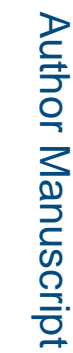

